\title{
Resveratrol oligomer structure in Dipterocarpaceaeous plants
}

\author{
Tetsuro Ito ${ }^{1,2}$
}

Received: 2 March 2020 / Accepted: 10 April 2020 / Published online: 30 April 2020

(c) The Author(s) 2020, Corrected Publication 2020

\begin{abstract}
Oligostilbenoids are a group of natural products derived from the oxidative coupling of $\mathrm{C}_{6}-\mathrm{C}_{2}-\mathrm{C}_{6}$ units found in some plant families. A structurally diverse chemical pool is produced after the successive regioselective and stereoselective oligomerization of resveratrol. This review describes the current status and knowledge of the structure of resveratrol oligomers (ROs) in Dipterocarpaceaeous plants (DPs). Beginning with the recently validated formation of ROs in DPs, each downstream conversion is described from the perspective of the resveratrol coupling mode. Particular emphasis is placed upon the regioselectivity of monomer- and dimer-derived radical-radical coupling processes, which are responsible for producing dimers, trimers, and tetramers with various cyclic frame skeletons, as well as related processes that result in highly condensed scaffolds, such as hexamers and octamers. Trimers in oxidized, dearomatized, and rearranged forms are also summarized, as well as the biogenic relationship between the compounds. Furthermore, emphasis is placed on the $O$ - and $C$-glucosides of ROs, as well as on the hetero-coupled ROs. In addition, several stereoisomers that originate from asymmetric carbons and the stereochemistry with respect to the conformation due to the chiral axis are described. Besides, NMR spectroscopic properties such as coalescence and anisotropy are briefly described. Approaches to determine absolute configuration are also summarized.
\end{abstract}

Keywords Dipterocarpaceae $\cdot$ Resveratrol $\cdot$ Oligomerization $\cdot$ Structural diversity

\section{Introduction}

In the plant kingdom, resveratrol oligomers (ROs) can be found in a number of plant families, such as the Dipterocarpaceae, Vitaceae, Cyperaceae, Fabaceae, Paeoniaceae, and Gnetaceae families [1-4]. The Dipterocarpaceaeous plant (DP) is the dominant plant family of Southeast Asia, with a total of 470 species [5, 6]. Indeed, plants in this family are a rich source of ROs, which are produced from the successive condensation of resveratrol (1: trans-3,5,4'trihydroxystilbene) (Fig. 1). The first RO was characterized from Hopea odorata in 1966 [7]; in the following 25 years, dozens of structurally related compounds have

Tetsuro Ito

tito@u-gifu-ms.ac.jp

1 Laboratory of Pharmacognosy, Gifu Pharmaceutical University, 1-25-4 Daigaku-nishi, Gifu 501-1196, Japan

2 Present Address: Laboratory of Pharmacognosy, Department of Pharmacy, Faculty of Pharmacy, Gifu University of Medical Science, 4-3-3 Nijigaoka, Kani, Gifu 509-0293, Japan been identified [1]. In recent years, several hundred ROs have been isolated from DPs with their structures determined accordingly [2]. In essence, this structural diversity stems from patterns of phenoxy radical-radical coupling that yield various fused-ring systems containing asymmetric carbons, which, in turn, give rise to regioisomerism and stereoisomerism. Structural diversity is further expanded by divergent structural modifications, such as oxidation, dearomatization, substituent rearrangement, and glucosylation [8]. Since wide-ranging bioactivity screens have been applied to RO and, in the process, their various activities identified, it remains essential to expand the current chemical library as well as to identify the exact structure of each isolate.

Scientific interest in ROs in DPs began in 1999. The impetus for this interest was due to a number of reasons. First, discovering the remarkable biological properties of the building block (BB), resveratrol, in human-health protection [9] and plant defense $[10,11]$ was a significant discovery. Second, several reports suggested (but did not prove) that certain types of ROs are pathway intermediates to further condensed components [12-15]. Third, according to some 


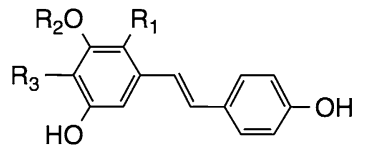

$$
\begin{array}{rr}
\text { resveratrol (1) } & : \mathrm{R}_{1}=\mathrm{R}_{2}=\mathrm{R}_{3}=\mathrm{H} \\
\text { piceid (2) } & : \mathrm{R}_{1}=\mathrm{R}_{3}=\mathrm{H}, \mathrm{R}_{2}=\mathrm{Glc} \\
4-C \text { - } \beta \text {-glucopyranosyl resveratrol (3) } & : \mathrm{R}_{1}=\mathrm{R}_{2}=\mathrm{H}, \mathrm{R}_{3}=\mathrm{Glc} \\
\text { 2-C- } \beta \text {-glucopyranosyl resveratrol (4) } & : \mathrm{R}_{1}=\mathrm{Glc}, \mathrm{R}_{2}=\mathrm{R}_{3}=\mathrm{H}
\end{array}
$$

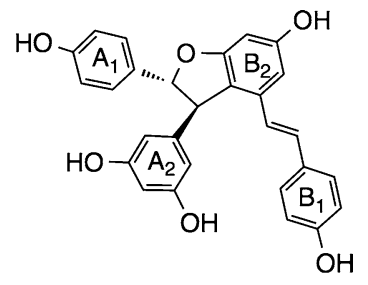

$(-)-\varepsilon$-viniferin (5)
Fig. 1 Structures of monomeric resveratrol derivatives (1-4) and 5

reports, many ROs of widely differing skeletal types are optically active, suggesting unique and/or distinct coupling mechanisms. Finally, the challenging structural-elucidation work simply triggered academic interest. Initial research goals mainly encompassed two topics: to define the structural diversity afforded by the condensation degree, varying skeletons, and isomerisms due to the number of asymmetric carbons found in this class of natural products; to gain insight into the research area of polyphenol (i.e., the chemistry of RO), which requires expanding the existing chemical library and accumulating spectroscopic details. In the last 2 decades, phytochemical studies have achieved the isolation and structural elucidation of roughly $200 \mathrm{ROs}$ in species belonging to the following seven genus: Vatica (V. rassak [16-19], V. pauciflora [20, 21], V. albiramis [22-25], and V. chinensis [25-27]), V. bantamensis [25], Vateria (V. indica) [28-33], Upuna (U. borneensis) [34-41], Cotylelobium, (C. lanceolatum) [42-44], Dipterocarpus (D. grandiflorus) [45, 46], Shorea (S. hemsleyana [33, 47-50], S. uliginosa [33, 51-54], and S. cordifolia [55]), and Hopea (H. parviflora [56-58] and $H$. utilis [59-61]). This review examines the structural aspects of RO, focusing on the derivatives mainly determined in our laboratory, and outlines their biogenetic relationship in combination with presenting skeletal diversity. For supporting information, a comprehensive list of RO in DP and diverse biological properties are summarized by Rivière et al. [4] and Keylor et al. [8], respectively.

\section{Definition}

Resveratrol can be widely found in the plant kingdom and, in particular, in the products of the phenylpropanoid pathway; it is responsible for transforming phenylalanine into 4-coumaroyl-CoA, which finally enters the stilbenoid-biosynthesis pathway [62]. ROs are metabolites found in a small set of phylogenetically distant plant families [4], the BB of which $\left(\mathrm{C}_{6}-\mathrm{C}_{2}-\mathrm{C}_{6}\right)$ is successively oligomerized after generating phenoxy radicals and highly active quinomethides (QM), followed by spontaneous regioselective radical-radical coupling, regiodivergent Friedel-Crafts reactions, nucleophilic trappings, and tautomerizations [8, 14].

ROs differ from most other polyphenols (e.g., flavonoids, pyrones, quinones, and their downstream products) by having comparatively less structural diversity due to small variations and the limited patterns of functional groups; by expanding the chemical pool by oligomerization, the production of various frame skeletons is ensured as well as the participation of $O$ - or $C$-glucoside (monoglucoside of resveratrol: 2-4 (Fig. 1)) as a BB. Additionally, they differ among themselves with respect to the inversion of the configuration of asymmetric carbons, which originate from the $\mathrm{C}_{2}$ units of the BBs. This results in the isolation of hundreds of derivatives that have characteristic stereoisomeric structural motifs, such as dihydrobenzofuran-, indane-, and bicyclo-ring systems that are conserved across DPs [2].

The researcher-friendly designating scheme has been applied to standardize the two oxygenated aromatic rings of phenol $\left(A_{1}\right)$ and the resorcinol rings $\left(A_{2}\right)$ in each resveratrol unit, in combination with a numbering order that denotes 14 carbons (1a-14a) starting from $A_{1}$. The next letter in the alphabet and the next numbering order are $\mathrm{B}_{1}, \mathrm{~B}_{2}$, and $1 b-14 b$, respectively, with regard to additional resveratrol units. When we explain the condensation modes of resveratrol units, such as regioselective radical-radical coupling, the numbering orders, $1-14$ and $1^{\prime}-14^{\prime}$, are applied (e.g., coupling modes $8-8^{\prime}, 8-10^{\prime}$, and $3-8^{\prime}$ ) according to the molecular species in question.

\section{RO structure in DPs}

Structurally diverse ROs can usually be found in planta as dimeric-tetrameric entities; to be sure, higher oligomers also exist. Because dimerization is the initial step in the global biosynthetic scheme of the chemical pool, it is crucial to clarify simple frame skeletons of the smallest oligomer to understand the further oligomerized (and more complex) skeletons of trimer-octamers lying downstream of biogenesis. ROs in DPs are regioselectively biosynthesized due to the coupling of oxidatively generated phenoxyl radicals $(\mathbf{1 A}-\mathbf{1 D})$, where the initial dimerization typically occurs through the $8-10^{\prime}$ coupling mode to produce various dimers that can be represented as (-)- $\varepsilon$-viniferin (5) (Figs. 1, 2) [11, 63]. The majority of resveratrol dimers are 8-10' linked, but many different coupling modes exist in nature (e.g., 8-8', 3-8', and 8-12'); these coupling modes (and the potential substrates involved) often vary according to the species being analyzed [2]. The diverse reactivity of further generated reactive QM species, such as $\mathbf{5 A - 5 E}$, in combination with 1A-1D further contribute to downstream regiodivergent reactions, which, in turn, results in the production of further condensed RO (Figs. 3, 4). In addition, 

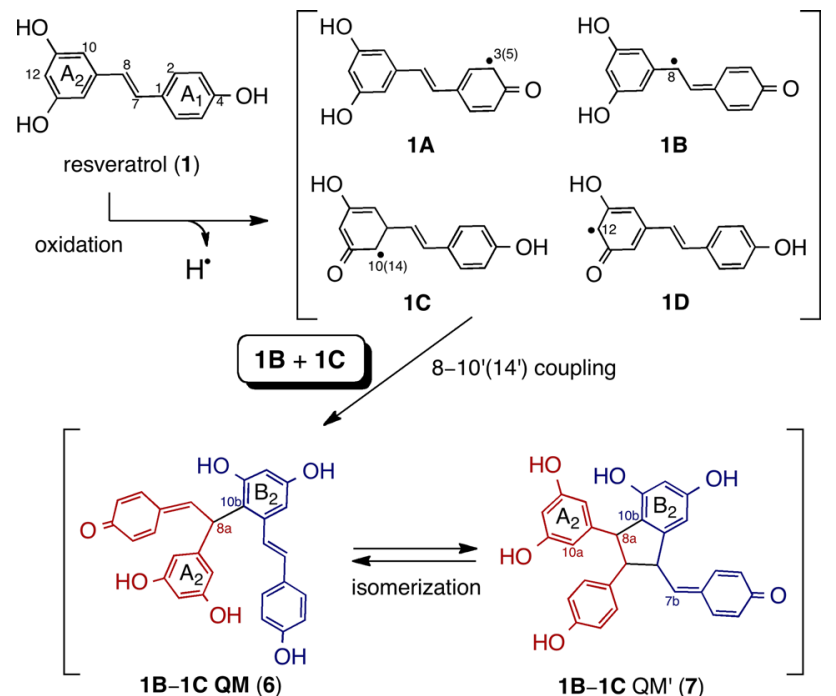

B-1C QM (6)

oxa-conjugate addition

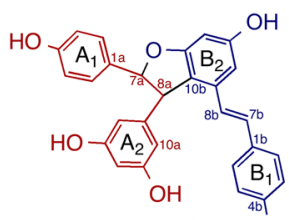

$\varepsilon$-viniferin (5) $\mathrm{OH}$

O- oxidation

cyclization
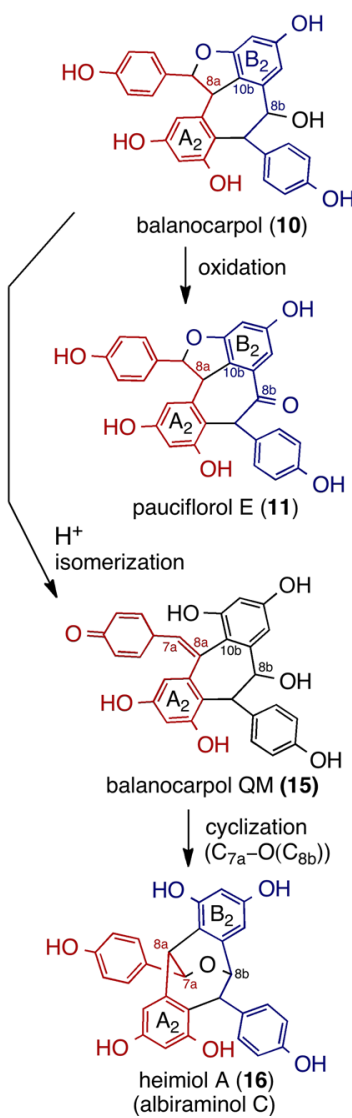
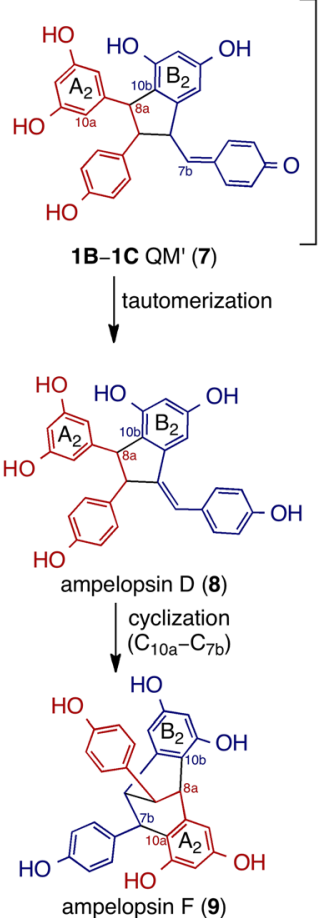

ampelopsin $\mathrm{F}(\mathbf{9})$

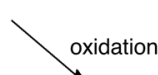

malibatol $\mathrm{A}$ (12)

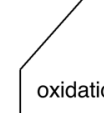

oxidation
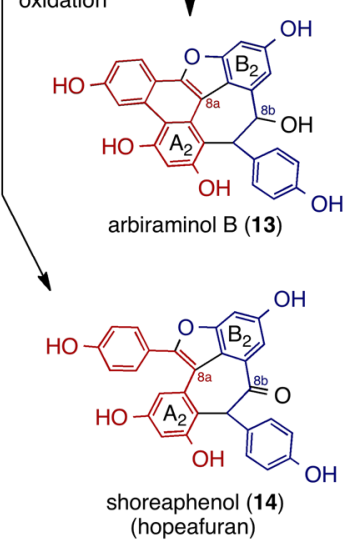

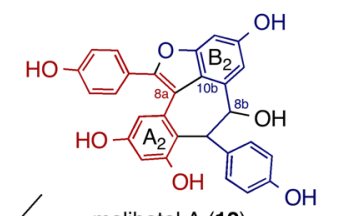

Fig. 2 Plausible biosynthetic pathway of the $8-10^{\prime}$ dimers

the glucoside of $\mathbf{1}$ not only stores resveratrol in cell tissues and prevents it from being oxidized, but it also contributes to the biosynthesis of $\mathrm{RO}$ glucosides, which further expands their chemical diversity. This can be seen in the rich isolation of 2-4 (Fig. 1).

Generally, asymmetric carbons exist in proportion to the oligomerization degree, e.g., in many cases, the dimers and tetramers of resveratrol have four and eight chiral atoms, respectively. Among the 200 ROs isolated from the DPs, dimers, trimers, and tetramers are common. This trend can be observed in other families, including Vitaceae [1-4]; however, the further condensed derivatives, such as hexamers and octamers, are not common. Compound $\mathbf{5}$ is one of the most abundant dimeric resveratrols, which has been isolated from the majority of RO-containing plant families, such as Dipterocarpaceae, Vitaceae, Cyperaceae, Fabaceae, Paeoniaceae, and Gnetaceae, among which DPs are known to produce (-)-form. Indeed, this issue is vital in considering an absolute configuration of biogenetically downstream chemicals. Because the structural diversity of RO can be attributed to skeletal variations and the presence of stereoisomerism, analyzing two- and three-dimensional structures is an interesting challenge, academically speaking.

\section{Two-dimensional structures and the biosynthetic scheme of simply oligomerized resveratrol}

In this section, representative ROs are discussed from the viewpoint of oligomerization degree and skeletal diversity with biosynthetic aspects. The listed compounds are prioritized to systematically depict a plausible biogenic relationship between compounds with topological differences. Indeed, our findings, which are based on experiments in the last 2 decades in combination with the existing literature, support the proposed biosynthetic aspects. In this section, each RO is delineated as a planar structure (Figs. 3, 4, 5, 6, $7,8)$.

\section{Resveratrol dimers}

The resveratrol dimers in DPs bear $8-10^{\prime} \mathrm{C}-\mathrm{C}$ bonds, which stems from the initial coupling (Fig. 2). The key dimeric intermediate, 1B-1C-QM (6), further undergoes particular cyclization(s) and tautomerization, thereby generating several different frame skeletons. As a result of the oxaconjugate addition, dimers bearing heterocyclic dihydrobenzofuran (e.g., $\varepsilon$-viniferin (5)) are generated. Alternatively, 5-exo-trig cyclization through $\mathrm{C}_{7 \mathrm{a}}-\mathrm{C}_{8 \mathrm{~b}}$ bond formation results in another QM (1B-1C-QM' (7)), which undergoes further tautomerization and 6-exo-trig cyclization through the $\mathrm{C}_{10 \mathrm{a}}-\mathrm{C}_{7 \mathrm{~b}}$ bond, which, in turn, results in resveratrol dimers with non-heterocyclic ring systems, such as indane 


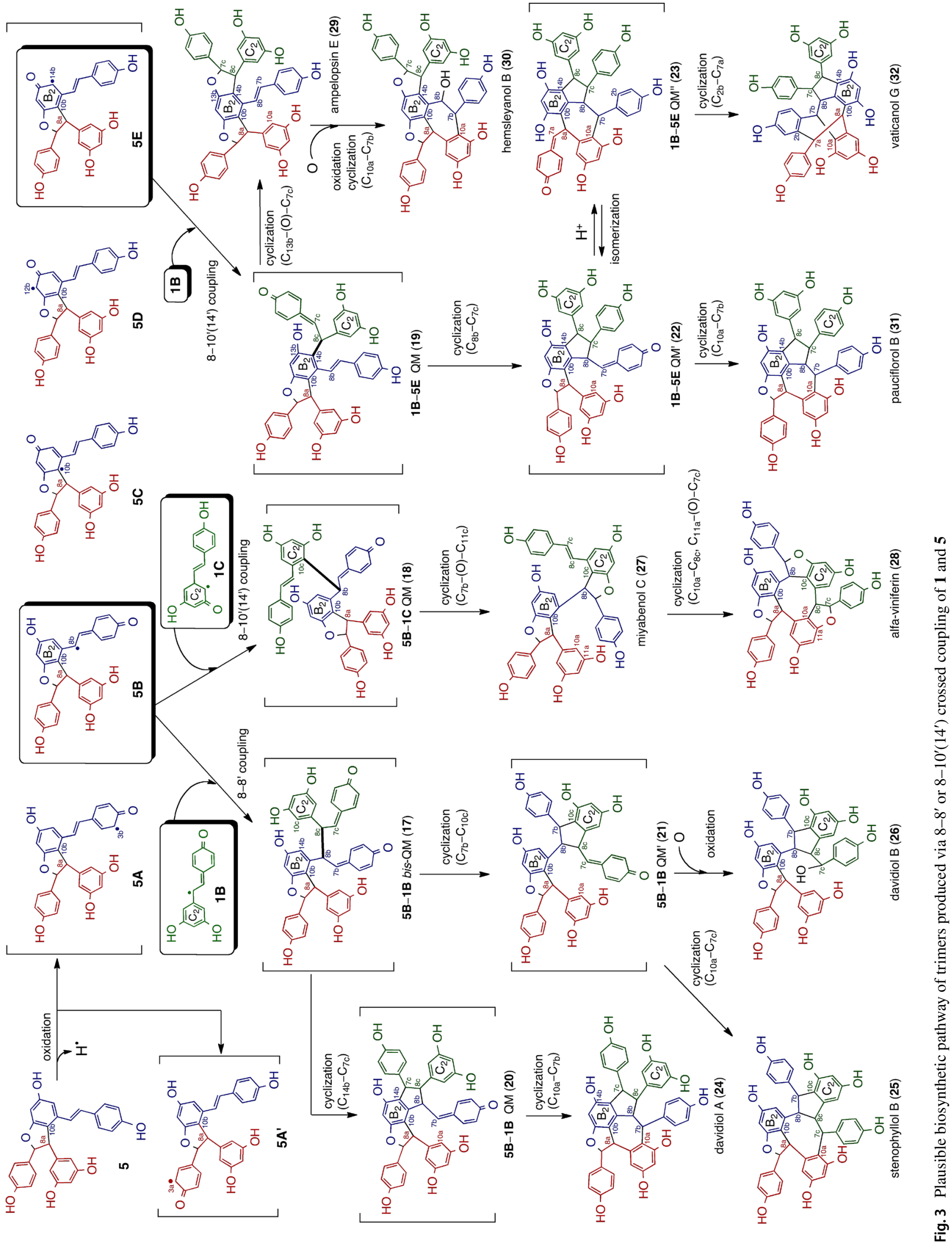



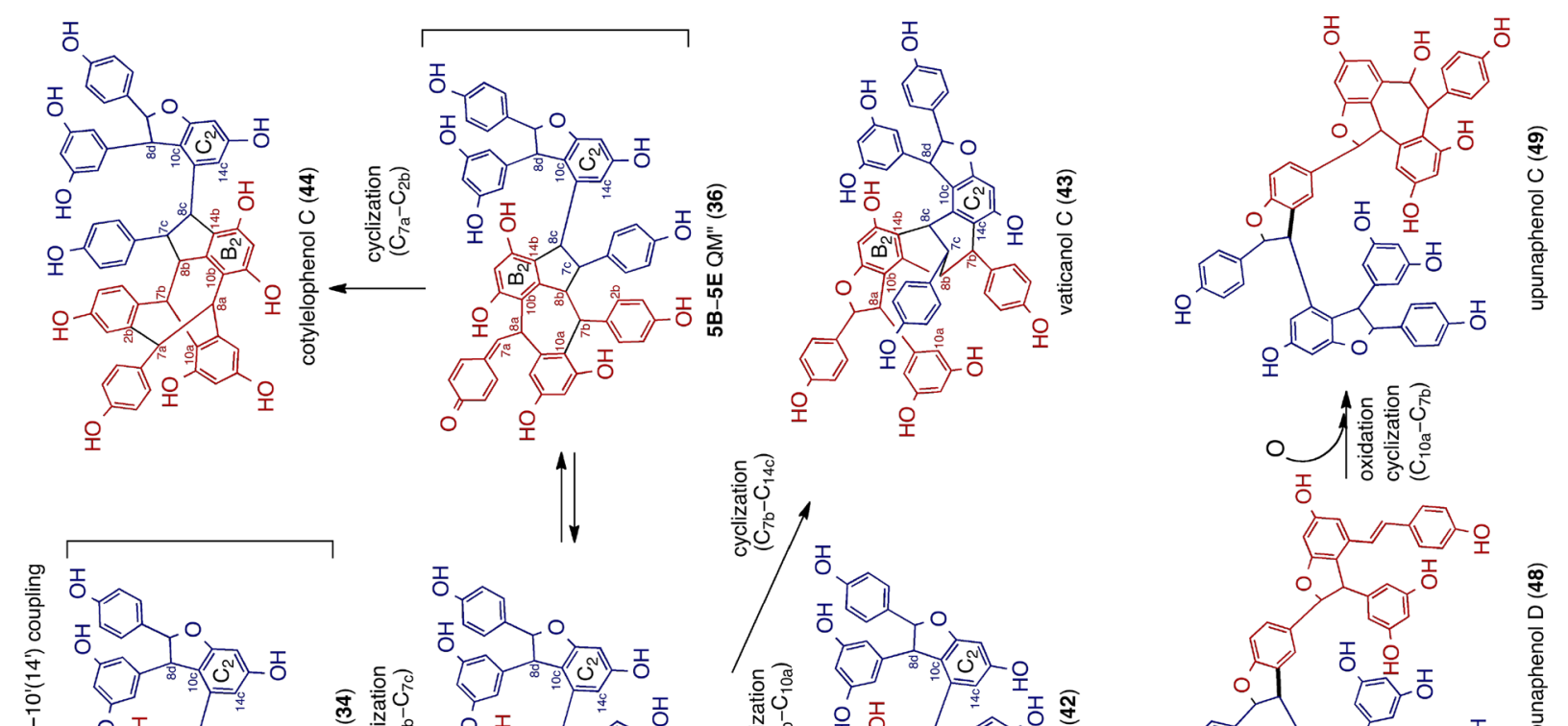

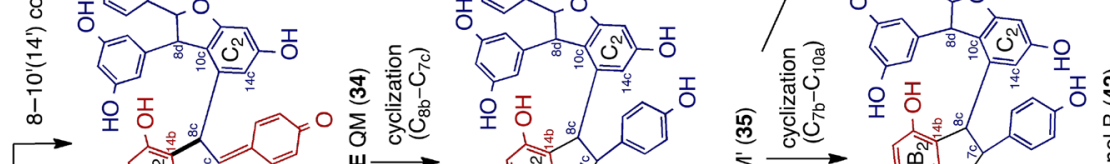
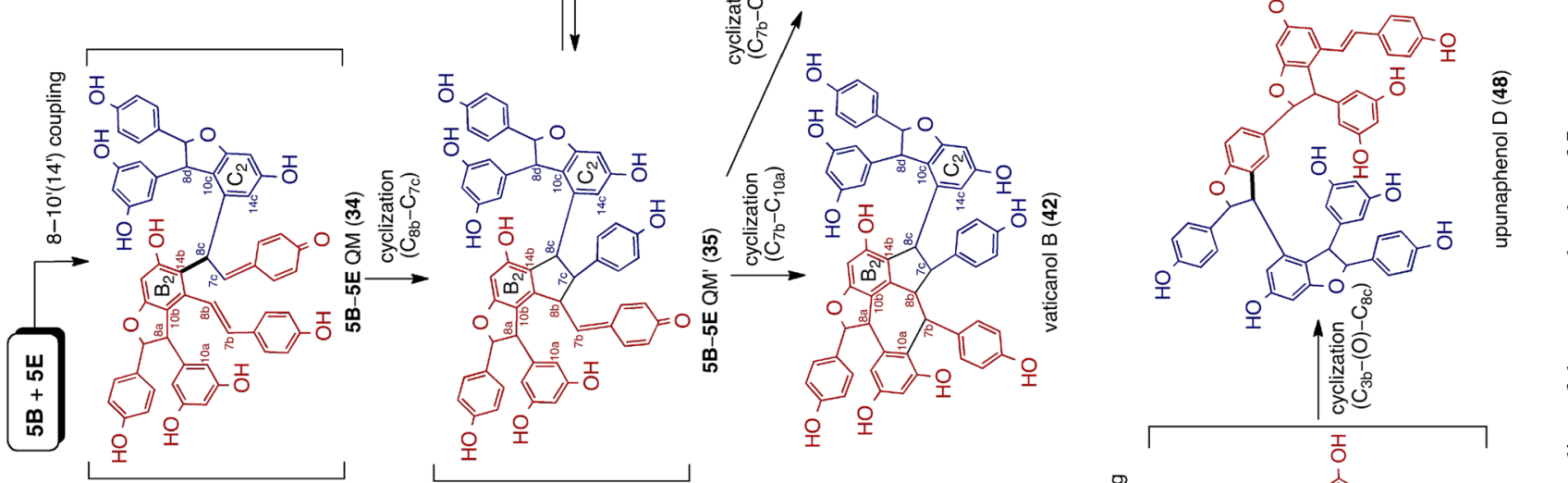

$n$
4
0
0
0
0
0
0
0
0
0
$\vdots$
0
$\Xi$
4
0
0
$\vdots$
$\vdots$
0

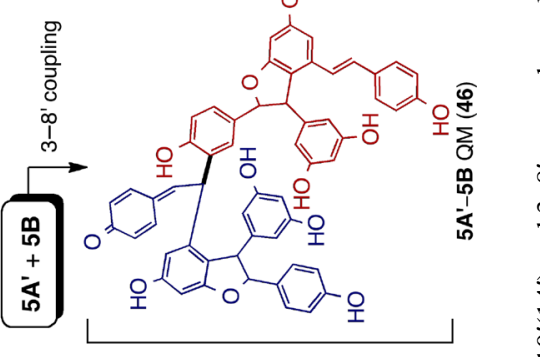

(1)
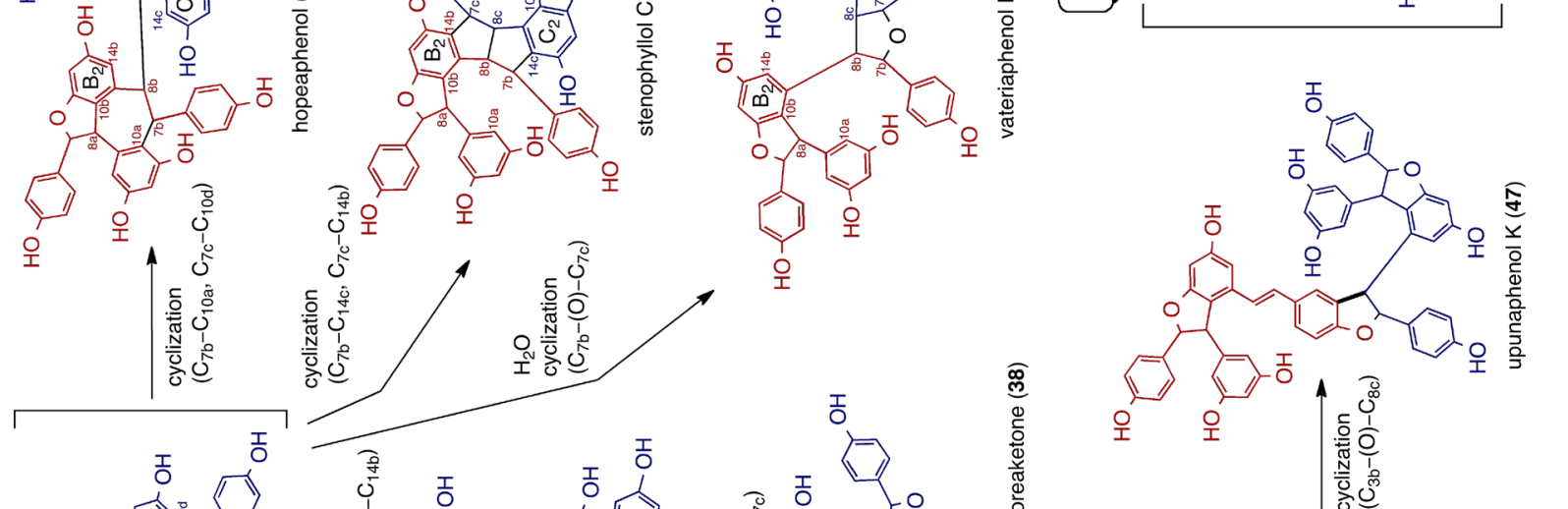

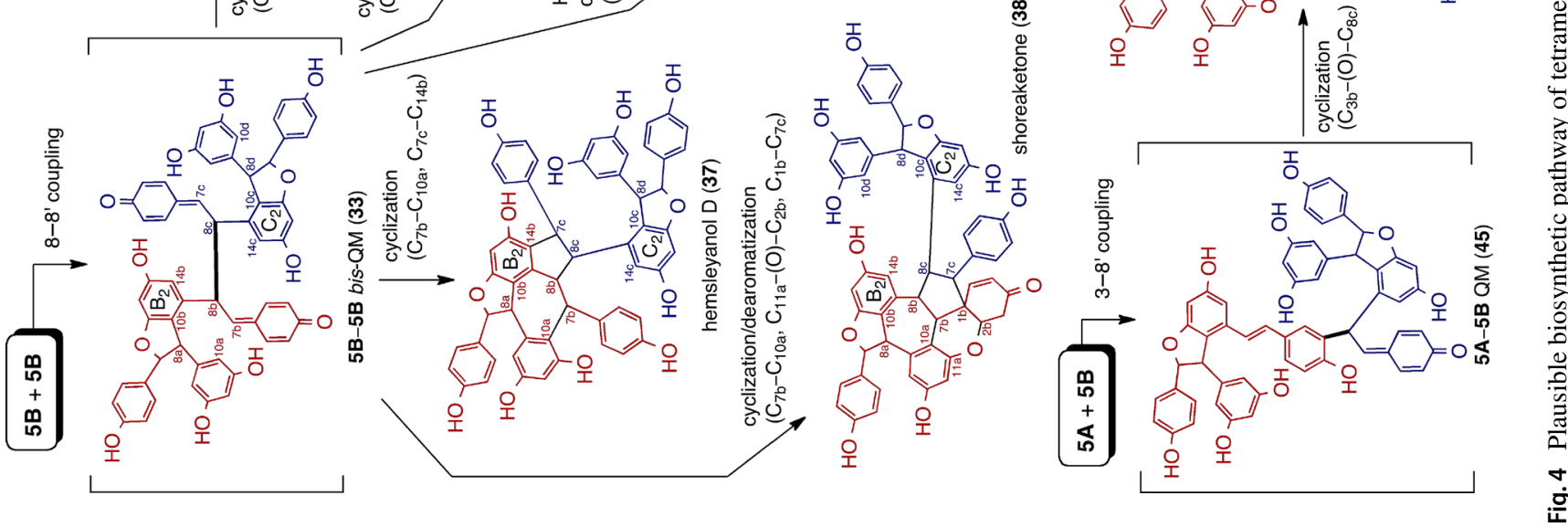




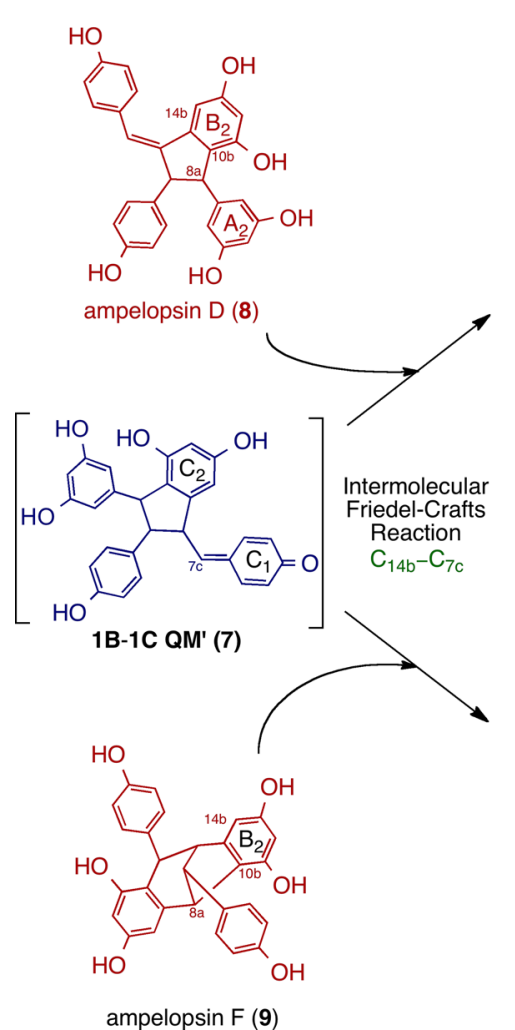

reactive $Q M$ species $(\mathbf{5 B} / \mathbf{5 E}$ and $\mathbf{1 B} / \mathbf{1 C})$ via the $8-8^{\prime}$ or $8-10^{\prime}\left(14^{\prime}\right)$ mode. The initially generated QMs (17-19) proceed through further regiodivergent cyclization to form various molecular species, with the subsequently generated QMs (20-23) acting as the presumed biosynthetic intermediates for a diverse series of resveratrol trimers (24-32) (Fig. 3).

Trimers derived from 5B-1B bis-QM (17) are referred to as " $8-8$ ' trimers", which is the naming scheme favored by Keylor et al. [8]. Although 8-8' trimers are a minority in DP, $\mathrm{QM}$ (17) can still undergo cyclization via $\mathrm{C}-\mathrm{C}$ bond formations, specifically $\mathrm{C}_{14 \mathrm{~b}}-\mathrm{C}_{7 \mathrm{c}}$ and $\mathrm{C}_{7 \mathrm{~b}}-\mathrm{C}_{10 \mathrm{c}}$ can be altered to form two QM intermediates: 5B-1B QM (20) and 5B-1B $\mathrm{QM}^{\prime}$ (21). This is supported by the existence of three ultimate products: davidiol A (24) [70, 71], stenophyllol B (25) [71], and davidiol B (26) [70]. Hitherto, a series of 5B-1B coupled trimers has been isolated from Vatica and Shorea species [21, 50]; however, further phytochemical investigations must be conducted to examine whether this class of trimers is ubiquitous.

The reactive intermediate, $\mathbf{5 B}$, could also couple to the other resveratrol phenoxy radical, $\mathbf{1 C}$, via the $8-10^{\prime}\left(14^{\prime}\right)$ mode to produce $\mathbf{5 B}-1 \mathrm{C} \mathrm{QM}(\mathbf{1 8})$ as well as a series of $8-10^{\prime}$ trimers. This intermediate follows oxa-conjugate addition(s) to produce miyabenol C (27) [72] and $\alpha$-viniferin (28) [73]. Several DPs belonging to the Shoreae family, such as Shorea and Hopea, produce 28 in rich quantities [50, 52, 74].

The production of plausible 1B-5E QM (19) followed by cyclization and isomerization results in other QMs, specifically 1B-5E QM' (22) and 1B-5E QM" (23). Indeed, the existence of said intermediates is strongly supported by the isolation of respective $8-10^{\prime}\left(14^{\prime}\right)$ trimers: ampelopsin $\mathrm{E}(\mathbf{2 9})$ [64], hemsleyanol B (30) [50], pauciflorol B (31) [21], and vaticanol $\mathrm{G}(32)$ [16]. In a fashion analogous to the biosynthesis of 10 via 5,29 can be altered to form 30 . Among these intermediates, $\mathbf{2 2}$ and $\mathbf{2 3}$ play a major role in the production of resveratrol trimers in several trimer-rich DPs classified as Vatica and Cotylelobium species [16, 19,44]. Similar to the $8-10^{\prime}$ dimeric resveratrol, $\mathbf{5}$, the downstream products of the 10-8'-coupled $\mathbf{1 B}-\mathbf{5 E}$ are widely distributed among the various species of DP.

\section{Resveratrol tetramers}

The major production of resveratrol tetramers takes place after the dimerization of dimers, wherein $\mathbf{5}$ plays a central role, as shown in Fig. 4. In the majority of resveratrol tetramers, the structure can be attributed to the presence of the configurationally conserved dihydrobenzofuran motif, which is a crucial issue in explaining the absolute configuration of high-order ROs. The production of resveratrol tetramers proceeds in a similar fashion to the resveratrol trimers via the initial formation of two QMs, specifically $\mathbf{5 B}-\mathbf{5 B}$ bisQM (33) (8-8' coupling mode) and 5B-5E QM (34) (8-10' 


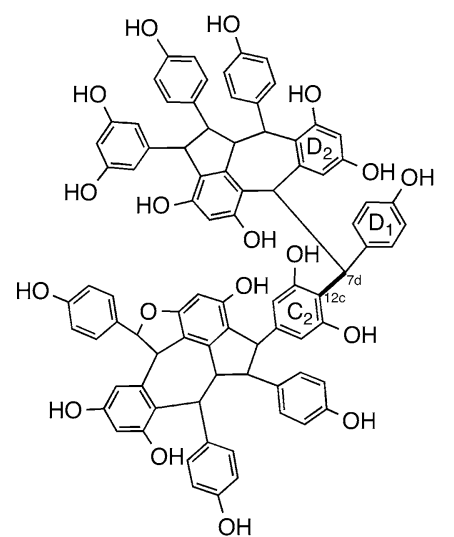

vaticanol $\mathrm{D}(\mathbf{5 2})$

[pauciflorol B (31) + 5E-1B QM" (23)]
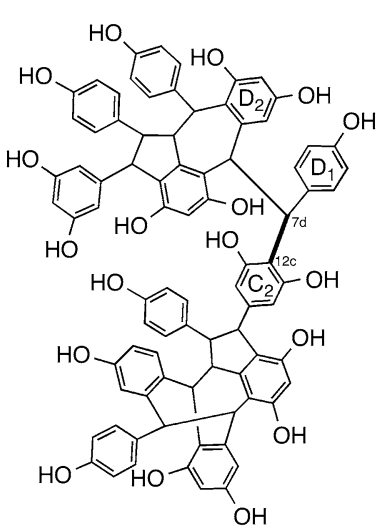

vaticanol $\mathrm{H}(53)$

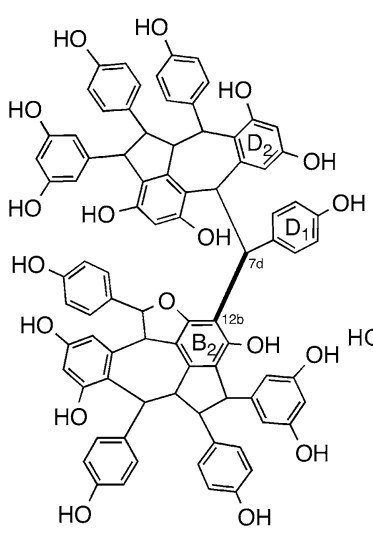

vaticanol I (54)

$31+5 E-1 B$ QM" (23)]

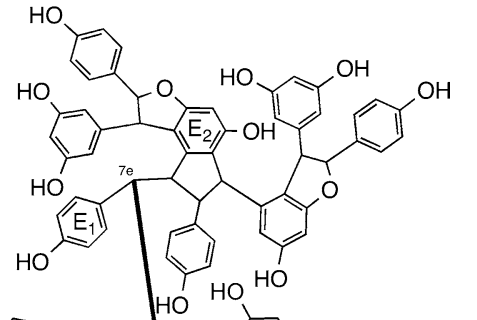

[vaticanol G (32) + 5E-1B QM" (23)]

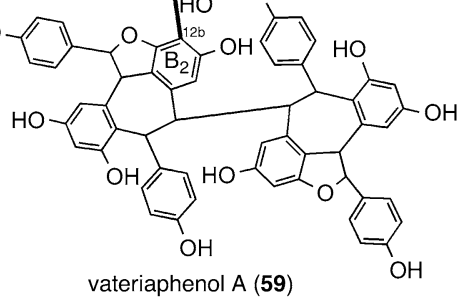

[hopeaphenol (39) + 5B-5E QM' (35)]

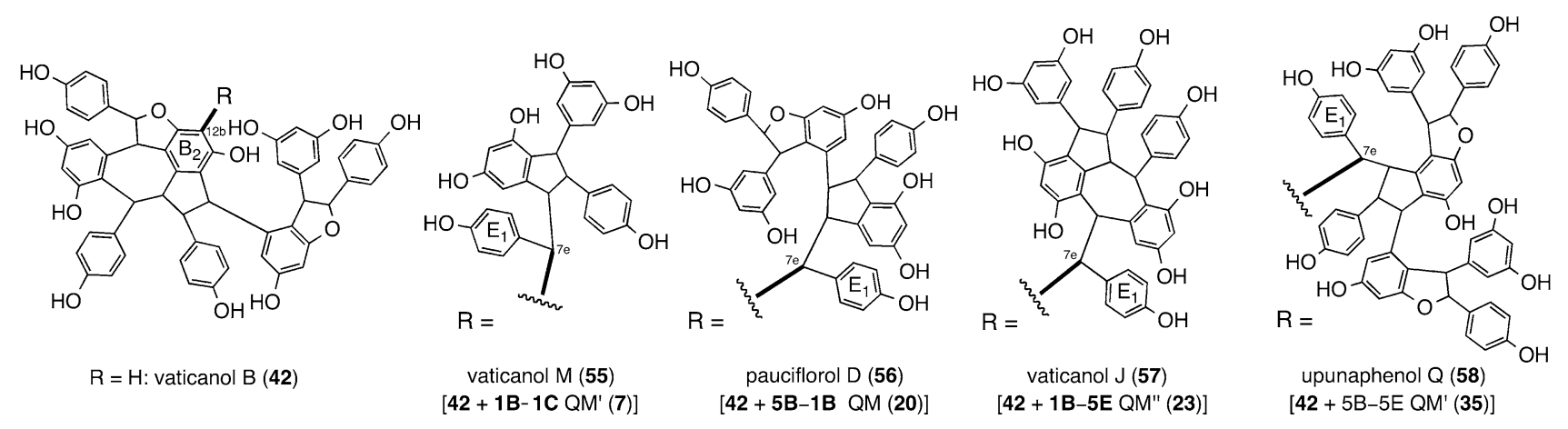

Fig. 6 Structures of highly condensed RO

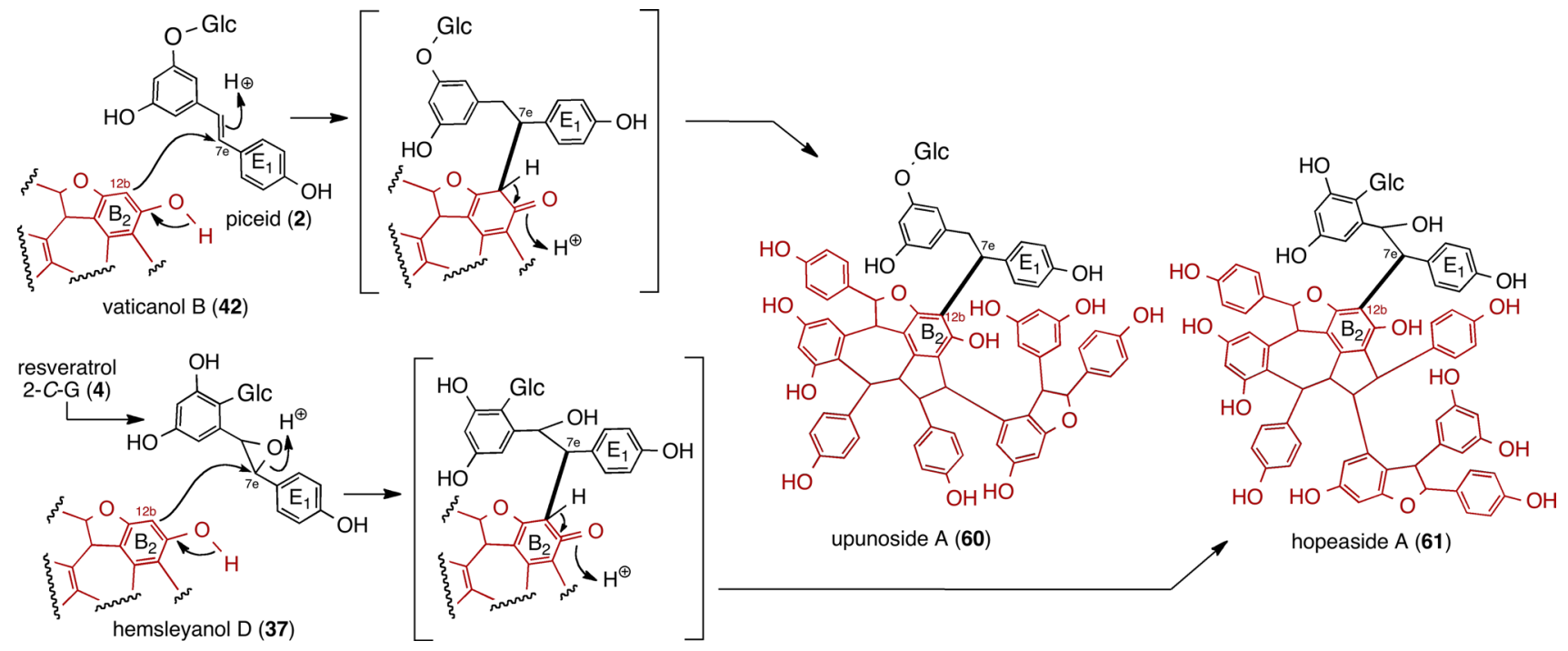

Fig. 7 Proposed biosynthesis of $O$ - and $C$-glucosides of pentamer

coupling mode), which mechanistically correspond to $\mathbf{1 7}$ and 19 for resveratrol trimers, respectively. The QM intermediates, $\mathbf{3 3}$ and 34, together with the further diversified QM scaffolds (5B-5E QM' (35) and 5B-5E QM" (36)) undergo numerous structural conversions, resulting in the production of a diverse chemical pool of $8-8^{\prime}$ and $8-10^{\prime}$ tetramers (37-44). Indeed, bicyclic structural motifs for 24, 31, and 32 can also be found in hemsleyanol D (37) [48], vaticanol 


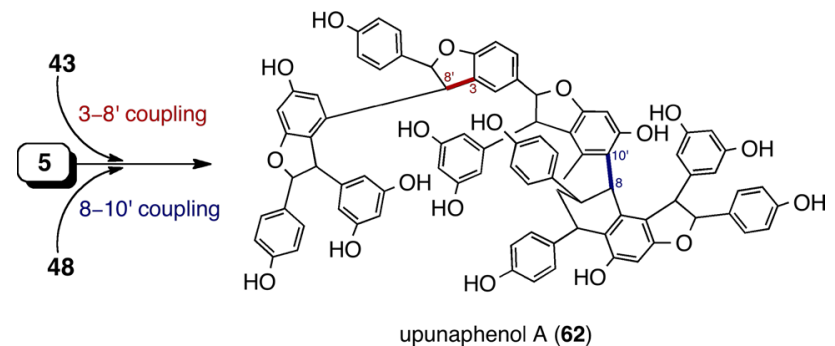

Fig. 8 Proposed biogenesis of 62 through $3-8^{\prime}$ and $8-10^{\prime}$ coupling

B (42) [19], and cotylelophenol C (44) [42], respectively. This indicates the existence of a similar mechanism with corresponding QM intermediates between the resveratrol trimers and tetramers.

In the case of 8-8'-tetramer biosynthesis, the bis-QM (33) is altered through regiodivergent cyclization(s) and dearomatization, resulting in the production of $\mathbf{3 7}$, shoreaketone (38) [33, 54], hopeaphenol (39) [7], and stenophyllol C (40) [71]. Molecules bearing the $\mathrm{C}_{2}$-axis of symmetry, formed via intramolecular cyclization (39: $2 \times 7$-exo trig; 40: $2 \times$ 5 -exo trig), are the characteristics of the $8-8$ ' tetramers. The other $\mathrm{C}_{2}$ molecule, vateriaphenol $\mathrm{F}$ (41) [28], has an additionally introduced oxygen atom on the symmetrical plane, which forms a tetrahydrofuran ring. It can be assumed that the tetrahydrofuran ring forms via the double addition of water across $\mathbf{3 3}$, followed by dehydrative cyclization. The biosynthetic mechanism for $\mathbf{3 8}$ involves subsequent cyclization via $\mathrm{C}-\mathrm{C}$ bond formation $\left(\mathrm{C}_{7 \mathrm{~b}}-\mathrm{C}_{10}\right.$ and $\left.\mathrm{C}_{1 \mathrm{~b}}-\mathrm{C}_{7 \mathrm{c}}\right)$ to give spirocyclic cyclopentane, which is followed by oxaconjugate addition to produce a $\mathrm{C}-\mathrm{O}$ bond $\left(\mathrm{O}_{11 \mathrm{a}}-\mathrm{C}_{2 \mathrm{~b}}\right)$. In turn, this results in the generation of the spirocyclohexene in the ultimate product [33]. Among 8-8' tetramers, 39 [7] is one of the most abundant tetramers in DPs.

Alternatively, the biosynthesis of $8-10^{\prime}$ tetramers can be explained by another primary intermediate, $\mathbf{3 4}$, which preferentially undergoes intramolecular 5-exo-trig cyclization through $\mathrm{C}_{8 \mathrm{~b}}-\mathrm{C}_{7 \mathrm{c}}$ isomerizing to $\mathbf{3 5}$ instead of 7-exo-trig cyclization as in $\mathbf{3 9}$, the latter of which would produce less types of frame skeletons than those from 33. The QM (35) and isomerized 5B-5E QM" (36) follow different cyclization pathways, resulting in the production of vaticanols $B$ (42), C (43) [19] (vat

diospyroidol [75]), and $\mathbf{4 4}$ [42]. In fact, $\mathbf{4 2}$, which is usually present with $\mathbf{4 3}$, is another abundant tetramer found in many DPs. It is interesting that the $8-10^{\prime}$ tetramers produced via $\mathbf{3 5}$ are specifically isolated from DPs, which further undergo downstream modification resulting in the scaffold characteristics, such as high-order oligomers (e.g., hexamers and heptamers).

The 3-8' connectivity is uncommon among the $\varepsilon$-viniferin-derived resveratrol tetramers. This is because there are fewer possible cyclization-reaction pathways compared with their $8-8^{\prime}$ and $8-10^{\prime}$ counterparts. Upon the oxidation of 5 and 3-8' dimerization, hypothetical para-QM intermediates (5A-5B QM (45) and 5 $\mathbf{A}^{\prime}-\mathbf{5 B}$ QM (46)) can follow oxa-conjugate addition to generate $3-8^{\prime}$ tetramers (upunaphenols K (47) [37] and D (48) [38]). The downstream analogues, such as upunaphenol C (49) [38] upon epoxidation and 7-exo-trig cyclization of $\mathbf{4 8}$, are also minorities. Currently, an array of 3-8' tetramers has only been found in the monotypic genus Upuna borneensis.

The other group of resveratrol tetramers is produced via $7-10^{\prime}\left(14^{\prime}\right)$ connectivity between two dimeric resveratrol units. The first isolation is vaticanol $\mathrm{K}(\mathbf{5 0})$ from Vatica chinensis, which possesses an unprecedented fused 2,7-dihydrooxepine-QM skeleton [27]. We presume that the plausible biogenesis, including the concerted intramolecular cyclization of two resveratrol dimers, is followed by desaturation extending conjugation. However, the further isolation of vaticanol $\mathrm{L}(\mathbf{5 1})$ with a $7-10^{\prime}$ bond suggests that the regioselective dimeric dimerization reactions occur due to the nucleophilic trapping of QM [26]. A similar scaffold of resveratrol tetramers with $7-10^{\prime}\left(14^{\prime}\right)$ bonds consists of cajyphenol A, which has been previously isolated from Cayratia japonica (Vitaceae) [76]. It has been proposed that cajyphenol A consists of metabolites after the cross coupling of quadrangularin A (8-8' resveratrol dimer) [77] and its penultimate biosynthetic intermediate, which involves nucleophilic trapping [8]. In the case of $\mathbf{5 0}$ and $\mathbf{5 1}$, an alternative to quadrangularin $\mathrm{A}$ is $8-10^{\prime}$ resveratrol dimer ( 8 and $\mathbf{9}$, respectively), which can undergo nucleophilic trapping onto 7 in a fashion similar to cajyphenol A, resulting in regioselective bond formation (Fig. 5). This oligomerization mode, also known as the intramolecular Friedel-Crafts reaction, is insignificant in the biogenesis of resveratrol tetramers.

\section{Highly condensed RO}

Vaticanols D (52), H (53), and I (54), are among the first identified hexameric resveratrol natural products, which were isolated from two DPs (Vatica rassak [16, 18] and Cotylelobium lanceolatum [44]) by us in the 2000s (Fig. 6). During parallel studies, various highly condensed ROs (HCRs) ranging from pentamers to octamers, have been discovered in DPs: Upuna borneensis [34, 40, 41, 78], Vateria indica $[32,78]$, and four Vatica species (V. pauciflora, V. arbiramis, $V$. chinensis, and $V$. bantamensis) [20, 23, 25]. The intramolecular Friedel-Crafts reaction occurring between two molecules is the mode of common HCRs, where the electron-rich resorcinol of the ROs also react with the QMs generated during the oligomerization of resveratrol. For instance, $\mathbf{5 2}$ and $\mathbf{5 4}$ are regioisomeric hexamers of the cross coupling of $\mathbf{3 1}$ and $\mathbf{2 3}$, which can be regarded as dimeric resveratrol trimers. When the counterpart of the trimeric unit 
is substituted with $\mathbf{3 2}, \mathbf{5 3}$ is generated. The other series of HCRs, specifically vaticanols M (55, resveratrol hexamer) [25], pauciflorol D (56, resveratrol heptamer) [20], vaticanol $\mathrm{J}$ (57, resveratrol heptamer) [16], and upunaphenol Q (58, resveratrol octamer) [78], have a common counter part of $\mathbf{4 2}$, wherein the electron-rich position $\left(\mathrm{C}_{12 \mathrm{~b}}\right)$ undergoes nucleophilic reaction with the respective QMs; that is, 7, 20, 23, and $\mathbf{3 5}$. Compound $\mathbf{5 8}$ is regarded as a dimeric molecule of 42, which is a major element of resveratrol tetramers in DP. Hitherto, the highest oligomerization degree of resveratrol has been achieved with resveratrol octamers, specifically dimeric resveratrol tetramers. Another resveratrol octamer, vateriaphenol A (59), can be biosynthesized when the vaticanol B-counterpart in upunaphenol Q is substituted with 39 [31, 32, 78]. This oligomerization mode, which involves the intermolecular trapping of QM intermediates, is common to many resveratrol pentamers that are biosynthesized after resveratrol tetramer (vaticanol B (42)) to be reacted with monomeric resveratrol glucoside (piceid (2)), resulting in the production of a pentamer, namely upunoside A $(\mathbf{6 0})$ (Fig. 7) [40]. The existence of said aglycons has never been demonstrated.

The similar biosynthetic machinery responsible for the production of a resveratrol pentamer glucoside is hopeaside A (61) (Fig. 7) [56]. 2- $C$ - $\beta$-glucopyranosyl resveratrol (4) proceeds by epoxidation; it is prone to attack by nucleophiles, such as the electron-rich arenes of $\mathbf{3 7}$, which produces 61.

As described above, major HCRs can be produced by the cross coupling of two ROs through an intermolecular Friedel-Crafts reaction in DPs. Unfortunately, little is known about examples of minor HCRs condensed only by radical couplings. The rare example of this is upunaphenol A (62) [41], which can be produced via radical coupling between 43 and 5 in the $3-8^{\prime}$ mode and/or 5 and 48 in the $8-10^{\prime}$ mode (Fig. 8).

\section{RO glucosides}

The chemical diversity of ROs in DPs also stems from modification by glucosylation, in which beta-glucopyranosyl groups are introduced prior to the oligomerization of resveratrol units. Collectively, they are referred to as the $O$ - and $C$-glucosides of ROs.

\section{O-Glucosides}

In the case of $O$-glucosides of RO $(O-\mathrm{G}-\mathrm{RO})$, it is evident that $\mathbf{2}$ is a vital BB in ROs, where, in the majority of cases, one glucopyranose can be found in said molecules. Currently, $O-\mathrm{G}-\mathrm{RO}$ bearing aglycon together with $\mathbf{2}$ have been isolated from many DPs belonging to different families, such as Vatica, Vateria, and Upuna. The majority of $O-\mathrm{G}-\mathrm{RO}$ co-exist with respective aglycon, such as dimers and hexamers; for instance, in vaticasides A-G [16, 17, 25] and pauciflorosides A-C [21], $O-\mathrm{G}-\mathrm{RO}$ are isolated together with their aglycons. Usually, in DPs, $O$-glucosides are found in less amounts compared with their corresponding aglycons. This suggests that the production of said molecules is the result of $\mathbf{2}$, which is introduced to the aforementioned biosynthetic pathway instead of $\mathbf{1}$.

So far, $O-\mathrm{G}-\mathrm{RO}$ have been determined to be enantiomerically identical with those of co-existing aglycons; however, the cordifolosides A (63) and B (64) with enantiomeric aglycons, which are isolated from Shorea cordifolia [55], are derived from (-)- and (+)-9, respectively (Fig. 9). Moreover, (-)-9 only co-exists as an aglycon in the plant material. Indeed, this suggests that particular DPs are capable of biosynthesizing $O-\mathrm{G}-\mathrm{RO}$ with enantiomeric aglycons, wherein the aliphatic 8-position of resveratrol is coupled with another aromatic $10^{\prime}$-position of $\mathbf{2}$.

\section{C-Glucosides}

With respect to $C$-glucosides of RO ( $C$-G-RO), chemical scaffolds have been identified after phytochemical studies on Shorea and Hopea species. In particular, it has also been demonstrated that the BBs, $4-C$ - $\beta$-glucopyranosyl resveratrol (3) and 4, co-exist in the respective species of Shorea (S. hemsleyana and S. uliginosa) and Hopea (H. parviflora and $H$. utilis). Notably, $C$-G-RO can be produced via their biosynthetic pathways. These are different from those of nonglucosylated ROs, which, according to previous phytochemical studies, have fewer structural correlations between C-G-RO and RO.

For example, phytochemical investigations of the extract of the stem bark of $S$. hemsleyana failed to isolate the nonglucosylated derivatives of hemsleyanosides A-F ( $C$-G-RO) and the $C$-glucosylated derivatives of hemsleyanols A-E (RO) [48-50]. Another crucial aspect of their structural diversity is that $\mathrm{C}-\mathrm{C}$ bond formation in the regioselective $8-10^{\prime}$ mode proceeds in an non-enantioselective fashion when the aliphatic 8-position of $\mathbf{3}$ is coupled to another aromatic $10^{\prime}$-position; this can be seen in the isolation of uliginoside $\mathrm{A}\left(\mathbf{6 5}: \mathrm{C}_{8 \mathrm{a}}(R)\right)$ and hemsleyanoside B (66: $\mathrm{C}_{8 \mathrm{a}}(S)$ ) from S. uliginosa (Fig. 10) [51,

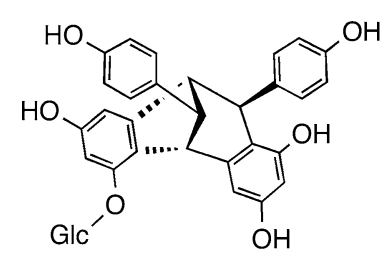

cordifoloside A (63)

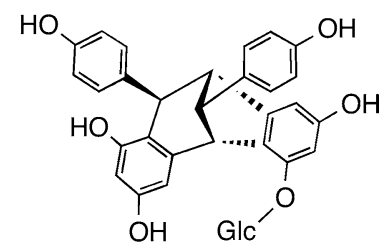

cordifoloside B (64)
Fig. 9 Structures of $O$-glucosides 63 and 64 

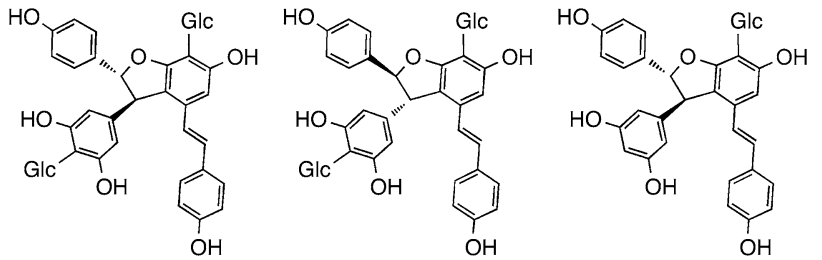

uliginoside $\mathrm{A}(65)$

hemsleyanoside $B(66)$

diptoindonensin $\mathrm{A}(67)$
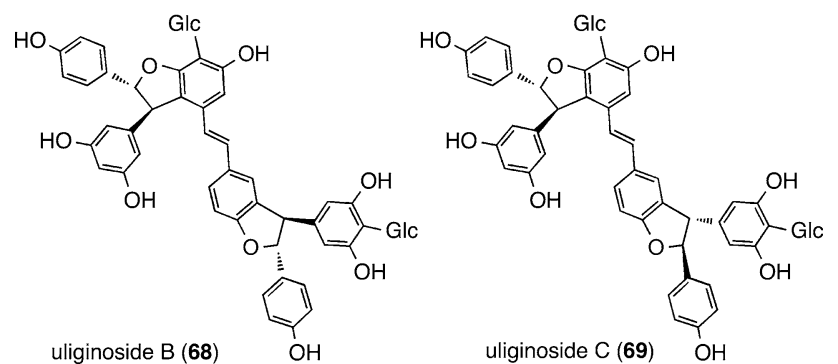

Fig. 10 Structures of $C$-glucosides with BB of 4-C- $\beta$-glucopyranosyl resveratrol

53]. Interestingly, the $8-10^{\prime}$ bond formation between the 8 -position of resveratrol and the $10^{\prime}$-position of $\mathbf{3}$ proceeds enantioselectively; moreover, the $C$-glucoside of (-)- $\varepsilon$-viniferin (diptoindonensin A (67) [79]) together with its biosynthetically downstream $C$-G-resveratrol trimers (uliginosides B (68) and C (69)) have been identified $[51,53]$. These trimers (68 and 69) also have antipodal dihydrobenzofuran moiety, which is produced after non-enantioselective $3-8^{\prime}$ bond formation, as seen in $\mathbf{6 5}$ and 66.

The chemical diversity of $C$-G-RO with BBs of $\mathbf{3}$ is the result of the regioselective intramolecular radical coupling and cyclization pathways. Typically, intramolecular cyclization or tautomerization of an intermediate para-quinone methide, which is also described for resveratrol dimers (Fig. 2), outcompetes most intermolecular processes. Some of the resultant dimers undergo further radical coupling through modes of $3-8^{\prime}, 8-8^{\prime}$, and $8-10^{\prime}\left(14^{\prime}\right)$ to produce high-order oligomers with 3 . Alternatively, it is assumed that the BBs of $\mathbf{4}$ are not displaced from 3 in the metabolic pathway; this is supported by the fact that no fused-ring systems involving $\mathbf{4}$ have been found. Instead, it is acceptable to assume that intermolecular functionalization by oxide of $\mathbf{4}$ occurs, wherein the electron-rich position of ROs reacts with their 7-position. Indeed, it is assumed that dimer (hopeaside D (70)), trimers (hopeasides $\mathrm{C}$ (71) and $\mathrm{E}(\mathbf{7 2})$ ), and pentamers (hopeasides A (61), B $\left(\mathrm{C}_{7 \mathrm{e}}\right.$-epimer of $\left.\mathbf{6 1}\right)$, and $\mathrm{F}(\mathbf{7 3})$ ) are produced after the crossed coupling of $\mathbf{4}$ with monomer (2), dimers (5 and 10), and tetramers ( 37 and $\mathbf{4 2}$ ), respectively (Fig. 11) [56, 59, 60].

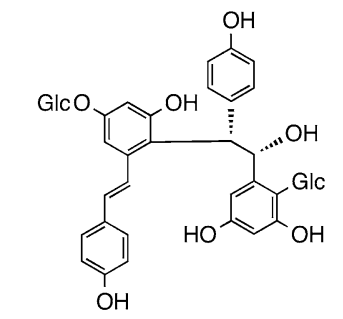

hopeaside D (70)

[piceid (2) + resveratrol 2-C-G (4)]

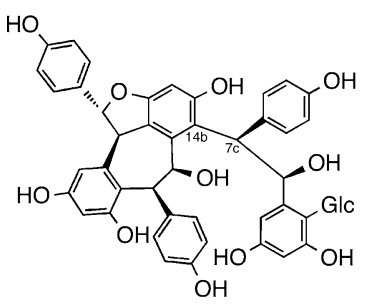

hopeaside $E$ (72)

[balanocarpol $(10)+4]$

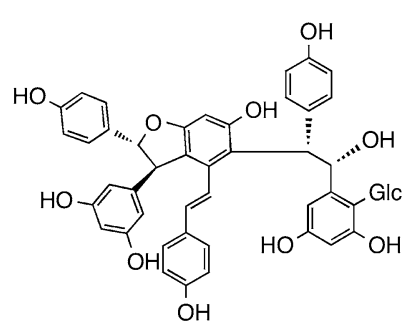

hopeaside $C(\mathbf{7 1})$

$[(-)$ - $\varepsilon$-viniferin $(5)+4]$

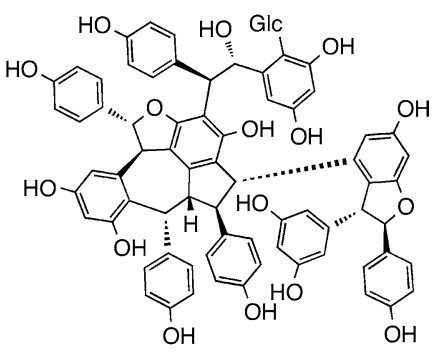

hopeaside $F(73)$ [vaticanol B (42) + 4]
Fig. 11 Structures of $C$-glucosides with BB of 2-C- $\beta$-glucopyranosyl resveratrol

\section{ROs as sources of chemical diversification}

Increased structural diversity is further produced by minor ROs and subsequent modifications, such as additional oxidation events and/or the attachment of additional atoms or groups. In addition, diversified ROs are further produced by dearomatization, tautomerization, substituent rearrangement, and so forth. Although the absolute quantity of said modified ROs is much less than those of precursor molecules, the isolation of such derivatives indicates a vast array of chemical RO scaffolding. Accordingly, we focus on such molecules to expand on the aspects of ROs.

\section{Dearomatized, rearranged, and/or oxidatively cleaved ROs}

The isolation of the dearomatized, rearranged, and/or oxidatively cleaved ROs demonstrates another level of chemical diversity. The first discovery of a dearomatized RO was achieved by the isolation of gnetin A (resveratrol dimer) with dearomatized resorcinol from Gnetum leyboldii (Gnetaceae) [80]. A subsequent report of leachianol C (resveratrol trimer) in Sophora leachiana (Fabaceae) by Ohyama et al. [81] was the first to identify dearomatized phenol in ROs. The finding of gnetin A and leachianols A and B [82], along with the isolation of kobophenol B (resveratrol tetramer) from Carex pumila (Cyperaceae) reported by Kawabata et al. [83], advanced the notion that the resveratrol units in ROs are condensed not only by regioselective radical-radical couplings followed by regiodivergent Friedel-Crafts 
cyclization, but also by a formal dearomative [3+2] annulation, forming the bicyclo[3.2.1]octedione. Alternatively, the dearomatized phenol structure in leachianol $\mathrm{C}$ can be regarded as the result of dearomative [3+3] annulation in forming the bicyclo[3.3.1]nonedione. The aforementioned resveratrol tetramer with the dearomatized phenol, 38 [33, 54], is formed by a different mechanism, where asymmetric dearomatization undergoes intramolecular-stereoselective cyclization (but not intermolecular-annulation reaction) in the biogenetic course.

The other examples of dearomatized ROs are vaticahainol B (74) (resveratrol dimer) [84], cotylelophenols B (75) and D (76) (resveratrol trimers) [43, 44], grandiphenol C (77) (resveratrol trimer) [45], and upunaphenol F (78) (resveratrol tetramer) [39] with dearomatized resorcinol, which, after oxidation, can be formed from the respective precursor molecules, 12, 31, 28, and $\mathbf{4 2}$ (Fig. 12).

The further isolation of rearranged $10-8^{\prime}$ trimers bearing a dibenzocycloheptane ring as well as cotylelophenols $\mathrm{A}(\mathbf{7 9})$ and $\mathrm{F}(\mathbf{8 0})[43,44]$ provides insight into the associated biogenic relationships and plausible intermediates (81-84) (Fig. 13). Indeed, the oxidation of $\mathbf{3 1}$ may produce the hypothetical intermediate $\mathbf{8 1}$, since $\mathbf{7 6}$ is a product of its epoxydation. Following the isomerization of $\mathbf{8 1}$, benzofuran6(3aH)-one 82 can also undergo epoxidation to generate intermediate $\mathbf{8 3}$, which is prone to isomerize to $\mathbf{7 5}$. A 1,2 aryl migration from $\mathbf{7 5}$ yields $\mathbf{7 9}$. Upon water trapping, $\mathbf{7 5}$ can undergo oxidative cleavage of its $\mathrm{C}_{7 \mathrm{a}}-\mathrm{C}_{8 \mathrm{a}}$ bond, followed by the hydrolysis of 4-hydroxybenzoate to obtain $\mathbf{8 0}$. Alternatively, $\mathbf{8 0}$ can possibly be derived from oxidative cleavage of another olefin of a plausible intermediate, specifically $\mathbf{8 4}$, which can be derived from the isomerization of $\mathbf{3 1}$.

Several rearranged and/or oxidatively cleaved resveratrol trimers have been isolated in DPs. A similar set of 1,2

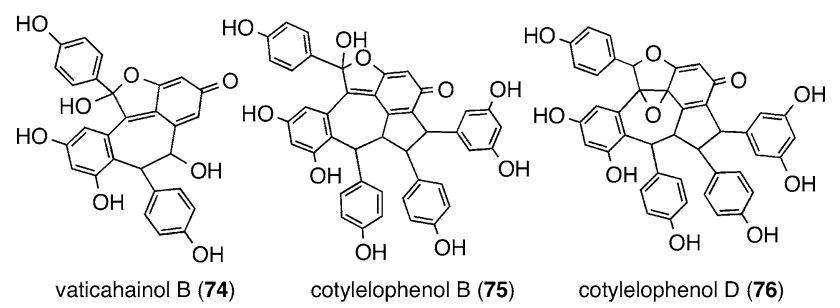

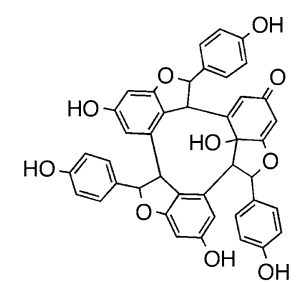

grandiphenol C (77)

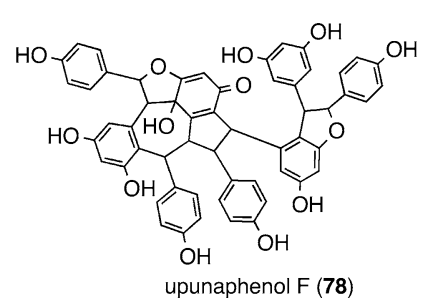

upunaphenol F (78)
Fig. 12 ROs with a dearomatized resorcinol ring

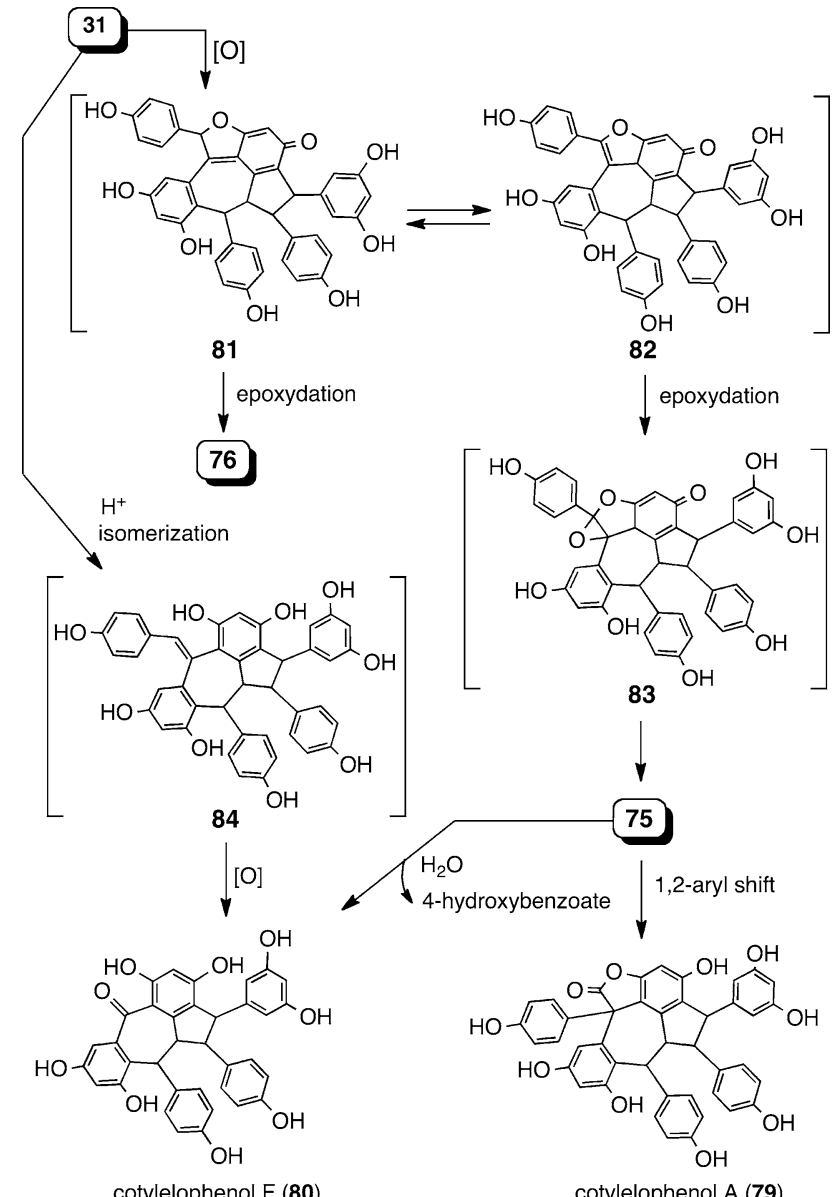

cotylelophenol A (79)

Fig. 13 Proposed biogenic relationship between $\mathbf{3 1}$ and the dearomatized, rearranged, and/or oxidatively cleaved metabolically downstream products

aryl migration has been observed for the $8-10^{\prime}$ dimer and $8-10^{\prime}$ trimer, wherein the 1,2 aryl rearrangement of $\mathbf{7 4}$ and 28results in vaticahainol A (85) [84] and grandiphenol D (86) [45], respectively (Fig. 14). The rearranged aryl group is also exemplified by the minor resveratrol hexamer, arbiraminol A (87) [23], which is presumably obtained owing to the 1,2 aryl rearrangement of ring $\mathrm{E}_{1}$. Pauciflorol $\mathrm{F}(\mathbf{8 8})$ [20], hemsleyanol E (89) [48], hopeachinol B (91) [85], and 92 form due to the oxidative cleavage of 8,74 , caraphenol A [86], and 27 (or 47), respectively. Diptoindonesin D (90) [87] and 89 differ only in the oxidation state at the $\mathrm{C}_{8 \mathrm{~b}}$ benzylic position. Further oxidation of $\mathbf{8 5}$ affords the ketoconjugated QM, hopeahainol A (93) [88], which is prone to lactone-ring hydration and, to obtain hopeanol B (94), goes through intramolecular 5-exo-trig Friedel-Crafts cyclization [86]. The oxidation of 10, which is followed by successive oxidative dearomatization, may result in the formation of hopeahainanphenol (95) [89].

An array of highly oxidized and structurally rearranged derivatives of $\mathbf{3 9}$ is also unique to DPs, which can 


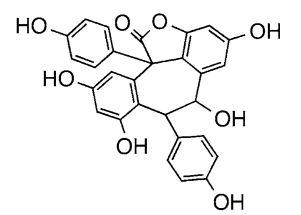

vaticahainol A (85)

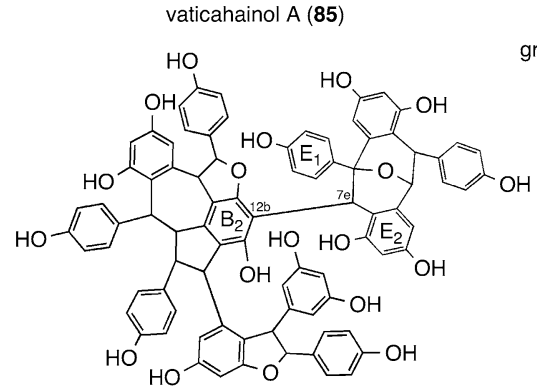

arbiraminol A (87)

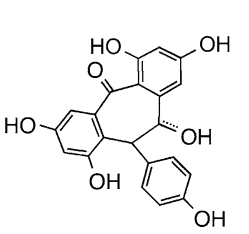

$\mathrm{R}=\mathrm{OH}$ hemsleyanol $\mathrm{E}(\mathbf{8 9})$ $\mathrm{R}=(\mathrm{O})$ diptoindonesin $\mathrm{D}(\mathbf{9 0})$

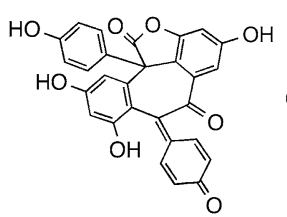

hopeahainol A (93)

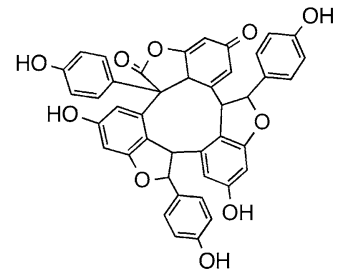

grandiphenol D (86)

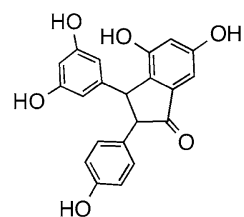

pauciflorol F (88)
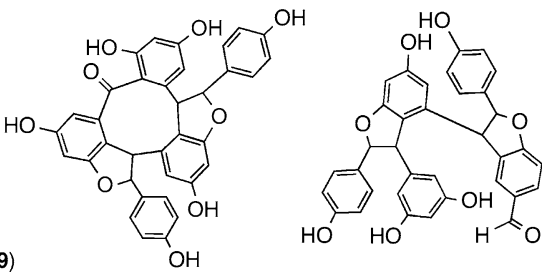

hopeachinol B (91)

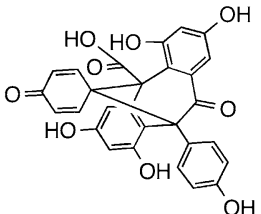

hopeanol B (94)
$\mathrm{OH}$

hopeahainanphenol (95)

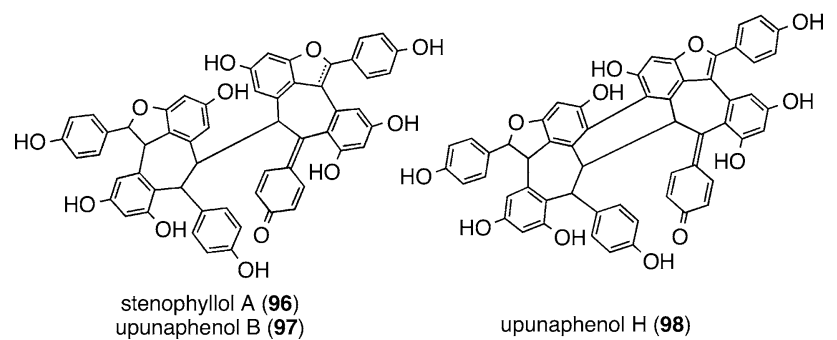

Fig. 14 Structures of ROs produced via oxidation, rearrangement, and dearomatization

be derivatized from the oxidative product of $\mathbf{3 9}$, which is stenophyllol A (96) (Fig. 14) [71]. When 96 further undergoes two- and four-electron oxidation, the benzofuran derivatives, upunaphenols B (97) [38] and H (98) [37], are respectively obtained, resulting in the extension of the conjugated system. Electron-mediated intramolecular $\mathrm{C}-\mathrm{C}$ bond formation for $\mathbf{9 8}$ can also be seen in the biogenesis of $\mathbf{1 3}$ (Fig. 2).

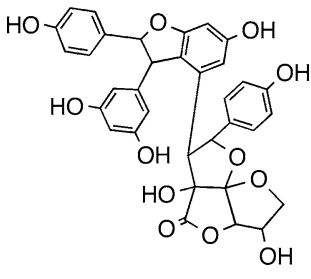

shorealactone (99)

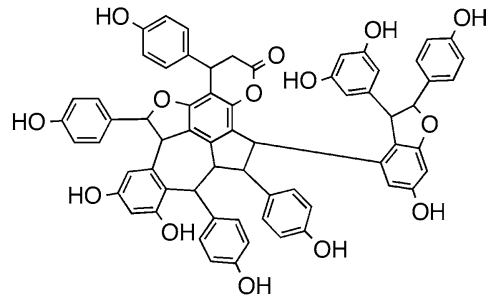

upunaphenol $L(100)$
Fig. 15 Structures of hetero-coupled ROs

\section{Hetero-coupled ROs}

In 2000, our team discovered and reported the structure of shorealactone (99) (Fig. 15), the ascorbyl-resveratrol dimer derivative isolated from Shorea hemsleyana, which is the first example of hetero-coupled ROs [47, 90]. The connectivity of the tricyclic-tetrahydrofuran core was the first instance found in naturally occurring polyphenols. Upon oxidation of 5 and ascorbic acid, the hypothetical QM intermediate, 5B, and monodehydroascorbic acid form a $\mathrm{C}-\mathrm{C}$ bond, which is followed by concerted regioselective cyclization pathways to generate 99. Later, an identical compound was isolated from the heartwood of Shorea laeviforia by Hirano et al. and given a second name; namely, laevifonol [91].

Upunaphenol L (100) is the first instance of lignostilbenoids in DPs, which is formed by the fusion of the electronrich arene of $\mathbf{4 2}$ and a phenylpropan unit [36]. It is assumed that ROs can undergo hetero coupling when the other reactive radical species exist.

\section{RO stereochemistry}

It is an interesting challenge to analyze the stereostructure of ROs. The central obstacles to elucidating the relative configuration consist of the following: poor prognosticators of the vicinal coupling constants required for configurational elucidation of the bicyclo five- and seven-membered ring systems; difficulties in affirming NOEs and ROEs in conventional two-dimensional nuclear magnetic resonance (NMR) spectra (NOESY and ROESY, respectively) due to the duplicated proton signals in determining substituent orientation and in elucidating the configuration and conformation of $\mathrm{C}_{2}$ molecules; the existence of the chiral axis. In addition, diminished NMR-signal intensity due to coalescence is also problematic when variable temperature NMR (VT-NMR) is not available. Another crucial property is anisotropy frequently observed in proton NMR ( $\left.{ }^{1} \mathrm{H}-\mathrm{NMR}\right)$, the analysis of which in combination with two-dimensional NMR data and three-dimensional molecular modeling would help in elucidating the relative configuration, especially when partial structures are connected through the chiral axis. 
As described above, DPs produce a number of OS analogues, which typically possess a common skeleton of 1,2-diaryl-dihydrobenzofuran stemming from (-)-5. This RO stereochemical homogeneity suggests that the downstream biosynthetic product of (-)-5 has the same absolute configuration in the 1,2-diaryl-dihydrobenzofuran skeleton. Alternatively, other types of ROs exist in this plant family, such as 63-66) (Figs. 9, 10). The fact that they bear antipodal stereochemistry in each 1,2-diaryl-dihydrobenzofuran and non-heterocyclic bicyclo[3.2.1] system demonstrates the need for various approaches in combination with the solid physicochemical approach to determine the absolute configuration, instead of speculating plausible biosynthetic precursors, such as (-)-5. Although the number of reports on RO stereochemistry is increasing, their absolute configuration is yet to be determined.

\section{Distereoisomerism}

It is known that distereoisomerism is a central factor in the structural diversity of ROs in DPs. In essence, ROs with various configurations can be attributed to the asymmetric carbons stemming from the $\mathrm{C}_{7}$ and $\mathrm{C}_{8}$ position of resveratrol. Isolated compounds exhibit diastereoisomerism as well as several configuration patterns, such as the four diastereomeric oxidized 8-10' dimers, 10 [66], (-)-ampelopsin A (101) [58], hemsleyanol A (102) [50], and acuminatol
(103) [92] (Fig. 16). These present the possible configurations of the two asymmetric carbons, $\mathrm{C}_{7 \mathrm{~b}}$ and $\mathrm{C}_{8 \mathrm{~b}}$, and can be differentiated according to the chemical shifts for aliphatic protons. The co-existence of $\mathbf{1 0}$ and $\mathbf{1 0 1}$ in several DPs reinforces the idea that the initial epoxidation step takes place in an enantioselective fashion, followed by the non-stereoselective 7-exo-trig Friedel-Crafts cyclization. The example of diastereomeric trimers are best shown by the 10-8' trimers, pauciflorols A (104) and B (31) [21] and the vaticanols A (105) [19] and E (106) [17]. Indeed, the generation of their biogenetic intermediate, 1B-5E QM (13), proceeds through the non-enantioselective $10-8^{\prime}$ coupling of (-)-5 and resveratrol, which enables the co-existence of both the configurations of the $\mathrm{C}_{8 \mathrm{c}}$ asymmetric carbon $\left(\mathrm{C}_{8 \mathrm{c}}(R)\right.$ : 104 and 106; $\mathrm{C}_{8 \mathrm{c}}(S)$ : 31 and 105). The epimeric 1B-5E QM intermediate (13) follows successive non-stereoselective Friedel-Crafts cyclization (5-exo-trig and 7-exo-trig cycles), thereby obtaining said diastereoisomeric divergent derivatives. In the case of tetrameric ROs, it is understandable that diastereoisomers stem from the non-enantioselective 8-8' coupling of two molecules of (-)-5, resulting in the production of a series of diastereoisomeric $\mathrm{C}_{2}$ molecules, specifically (-)-39 [7], (+)-isohopeaphenol (107) [30], pauciflorol C (108) [21], and vatreriaphenols B (109) [31] and C (110) [30]. The relative configuration of these diastereomers can be determined using the data obtained from the differential NOE, NOESY, and/or ROESY experiments.

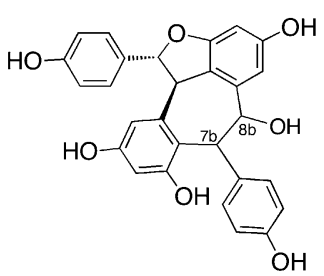

\begin{tabular}{lcc} 
& $\mathrm{C}_{7 \mathrm{~b}}$ & $\mathrm{C}_{8 \mathrm{~b}}$ \\
\hline balanocarpol (10) & $S$ & $S$ \\
(-)-ampelopsin A (101) & $R$ & $S$ \\
hemsleyanol A (102) & $S$ & $R$ \\
acuminatol (103) & $R$ & $R$ \\
\hline
\end{tabular}
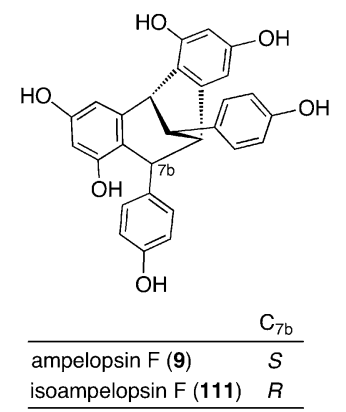

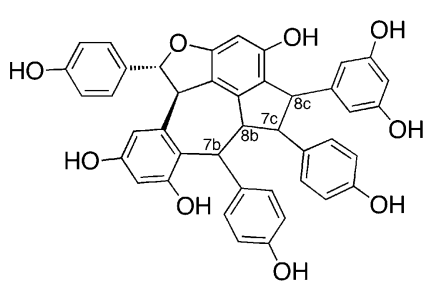

\begin{tabular}{lcccc} 
& $\mathrm{C}_{7 \mathrm{~b}}$ & $\mathrm{C}_{8 \mathrm{~b}}$ & $\mathrm{C}_{7 \mathrm{c}}$ & $\mathrm{C}_{8 \mathrm{c}}$ \\
\hline pauciflorol B (31) & $R$ & $R$ & $S$ & $S$ \\
pauciflorol A (104) & $R$ & $R$ & $R$ & $R$ \\
vaticanol A (105) & $R$ & $S$ & $S$ & $S$ \\
vaticanol E (106) & $S$ & $S$ & $R$ & $R$
\end{tabular}

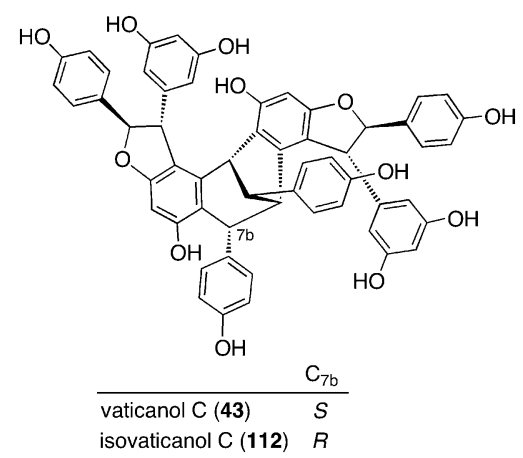

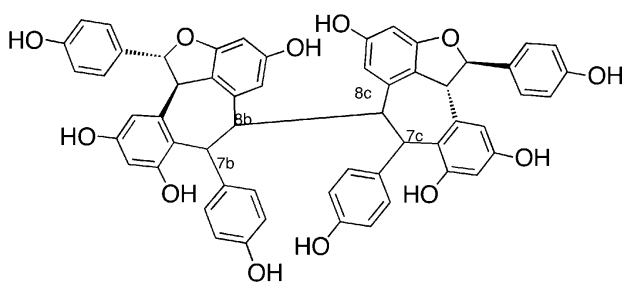

\begin{tabular}{lcccc} 
& $\mathrm{C}_{7 \mathrm{~b}}$ & $\mathrm{C}_{8 \mathrm{~b}}$ & $\mathrm{C}_{7 \mathrm{c}}$ & $\mathrm{C}_{8 \mathrm{c}}$ \\
\hline (-)-hopeaphenol (39) & $R$ & $S$ & $R$ & $S$ \\
(+)-isohopeaphenol (107) & $S$ & $R$ & $S$ & $R$ \\
pauciflorol C (108) & $S$ & $S$ & $S$ & $R$ \\
vateriaphenol B E (109) & $R$ & $S$ & $S$ & $R$ \\
vateriaphenol B E (110) & $S$ & $S$ & $S$ & $S$ \\
\hline
\end{tabular}
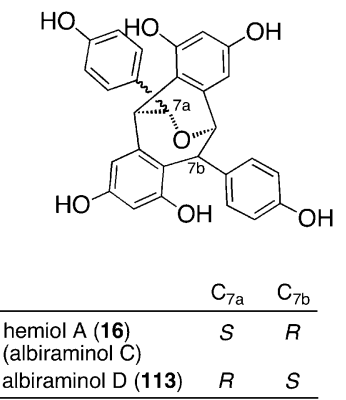

Fig. 16 Diastereomeric ROs 


\section{Rotational isomerism}

Compound $\mathbf{3 8}$ is a precedent of the atropisomeric ROs having two configurationally stable two rotational isomers (extended rotamer 38a and compact rotamer 38b) (Fig. 17) at an ambient temperature in the NMR time scale [33, 54]. The separation of each conformer is unaccomplished due to exchangeable properties through the chiral axis. Although its peracetate only has one conformer, the deacetylated product has signal duplications due to atropisomerism. Changes in the ratio of the two conformers and the various solvents of the VT-NMR as well as the cross peaks due to conformational exchange observed in the NOESY experiments can be attributed to rotational isomerism. The complete and unequivocal assignment of proton and carbon resonances of the two rotational isomers is demonstrated through structural analysis. The rotational state of the rotamers can be defined using NOESY experiments, which show correlations between $\mathrm{H}_{8 \mathrm{c}}$ and $\mathrm{H}_{14 \mathrm{c}}$. Accordingly, it is possible to differentiate the two rotamers. Each conformation is supported by the anisotropy that is explained by the different chemical shifts of $\mathrm{H}_{2 b}$ and $\mathrm{H}_{14 \mathrm{c}}$ in the two rotamers. Decisive evidence for the absolute configuration can be obtained by the acidcatalyzed rearrangement of $\mathbf{3 8}$, resulting in the formation of a monoalkyl ether of the known resveratrol tetramer; namely, (+)-107.

The second instance of an atropisomeric RO is 72 [59]. Because $\mathbf{7 2}$ has covalent $\mathrm{C}-\mathrm{C}$ bonds connecting two partial structures (i.e., 10 and 4)), the configurational relationship between them and the conformational determination due to the rotational isomerism are critical issues in the stereostructure analysis. The NMR spectra in $\mathrm{MeOH}-d_{4}$ show multiplicity, which possibly stems from the rotational isomerism through the chiral axis, $\mathrm{C}_{14 \mathrm{~b}}-\mathrm{C}_{7 \mathrm{c}}$, displaying signals due to a major conformer and a minor one. Moreover, when the material recovered from the $\mathrm{MeOH}-d_{4}$ solution is redissolved in acetone- $d_{6}$, the ${ }^{1} \mathrm{H}$ NMR spectrum only shows major conformers. These results indicate that $\mathbf{1}$ undergoes conformational isomerism in $\mathrm{MeOH}$, an observation that is further confirmed by the NOESY correlations by chemical

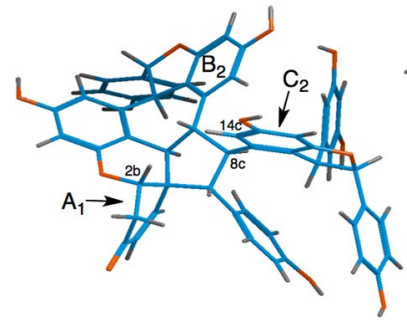

Extended rotamer: $\mathbf{3 8 a}$

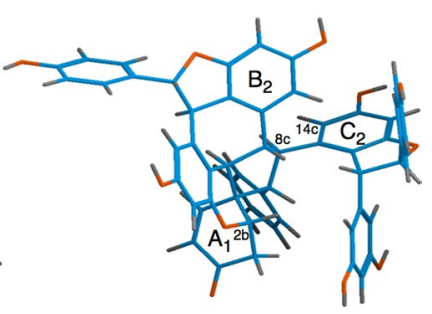

Compect Rotamer: 38b
Fig. 17 Energy-minimized conformations of the two atropisomer structures of hetero-coupled ROs exchange for the aromatic signals. Another important issue associated with the determining the absolute configuration of $\mathbf{7 2}$ is the comparative-configurational analysis, which is conducted using the $\beta$-D-glucopyranosyl group and has been previously demonstrated with respect to $\mathbf{7 1}$ and $\mathbf{7 0}$ [56].

\section{Steric hindrance upon rotation of aromatic rings}

The restricted rotation of aromatic substituents is a wellrecognized property, which provides crucial information in elucidating configuration and conformation. Compound 32, for example, the two set of aromatic protons $\left(\mathrm{H}_{2 \mathrm{c}} / \mathrm{H}_{6 c}\right.$ and $\mathrm{H}_{3 \mathrm{c}} / \mathrm{H}_{5 \mathrm{c}}$ ) in a 4-hydroxyphenyl group, is non-equivalent due to the hindered rotation about the $\mathrm{C}-\mathrm{C}$ bond $\left(\mathrm{C}_{1 \mathrm{c}}-\mathrm{C}_{7 \mathrm{c}}\right)$, which can be seen in the NMR with four independent ${ }^{1} \mathrm{H}$ and ${ }^{13} \mathrm{C}$ broad signals $\left(\mathrm{H}_{2 \mathrm{c}}, \mathrm{H}_{3 \mathrm{c}}, \mathrm{H}_{5 \mathrm{c}}\right.$, and $\mathrm{H}_{6 \mathrm{c}} ; \mathrm{C}_{2 \mathrm{c}}, \mathrm{C}_{3 \mathrm{c}}, \mathrm{C}_{5 \mathrm{c}}$, and $\mathrm{C}_{6 c}$ ) [16]. The other examples are presented by isoampelop$\sin \mathrm{F}$ (111: $\mathrm{C}_{7 \mathrm{~b}}$-epimer of 9) [93], isovaticanol C (112: $\mathrm{C}_{7 \mathrm{~b}}$-epimer of 43) [21], 79 [44], and arbiraminol D (113: $\mathrm{C}_{7 \mathrm{a}, 7 \mathrm{~b}}$-diastereomer of 16) [22]. The NMR behavior of $\mathbf{7 9}$ is particularly significant because all 4-hydroxyphenyl groups are rotationally restricted, wherein complete structural elucidation is achieved by the aid of the VT-NMR experiment, as was done for 32 (Fig. 18). The energy-minimized structure suggests that the higher field shifts of aromatic protons on rings $A_{1}-C_{1}$ can be explained by the anisotropic effects caused by the neighboring rings (Fig. 19). For example, at $-0{ }^{\circ} \mathrm{C}$, where $\mathrm{H}_{5 \mathrm{a}}$ and $\mathrm{H}_{6 \mathrm{a}}$ can be observed at $\delta 5.90$ and 5.70, the higher field shifts are caused by the effect of ring $\mathrm{B}_{1}$. The effects of both rings $\left(A_{1}\right.$ and $\left.C_{1}\right)$ results in the higher field shifts of $\mathrm{H}_{2 \mathrm{~b}, 6 \mathrm{~b}}$ and $\mathrm{H}_{3 \mathrm{~b}, 5 \mathrm{~b}}$. At $-90{ }^{\circ} \mathrm{C}$, where the aromatic proton on ring $\mathrm{C}_{1}$ is observed as four separated signals, the higher field shift of $\mathrm{H}_{3 \mathrm{c}}$ can be observed at $\delta 6.08$, which can be attributed to the anisotropic effect of ring $\mathrm{B}_{1}$. As can be seen in the structural elucidation of $\mathbf{7 9}$, the exact understanding of the coasealence caused by the hindered rotation of aromatic rings, as well as the accompanying anisotropic effects on aromatic protons, helps in determining the relative configuration and conformation of ROs.

When the partial structures connected through the $\mathrm{C}-\mathrm{C}$ bond increase in size, the rotational barriers also increase, which results in a stable conformer. Examples of this can be seen in $\mathbf{4 2}$ and 37 with the 3-(3,5-dihydroxyphenyl)6-hydroxy-2-(4-hydroxyphenyl)-2,3-dihydrobenzofuran4-yl group (1,2-diaryl-dihydrobenzofuran) connected to the dibenzobicyclo[5.3.1] octadiene core, where $\mathrm{H}_{8 \mathrm{c}}$ and $\mathrm{H}_{14 \mathrm{c}}$ are situated in syn orientation. The hindered rotation and conformational stability in such molecules can also be enhanced by attractive forces, such as $\mathrm{CH}-\pi$ and $\mathrm{OH}-\pi$ interactions [94, 95].

Alternatively, the particular alignment of partial structures could weaken the aforementioned rotational restrictions, which, in turn, can causing coasealence as well as 


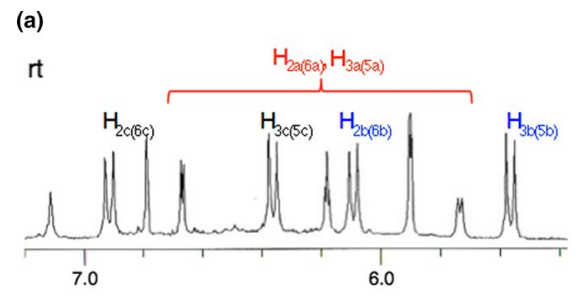

$0^{\circ} \mathrm{C}$
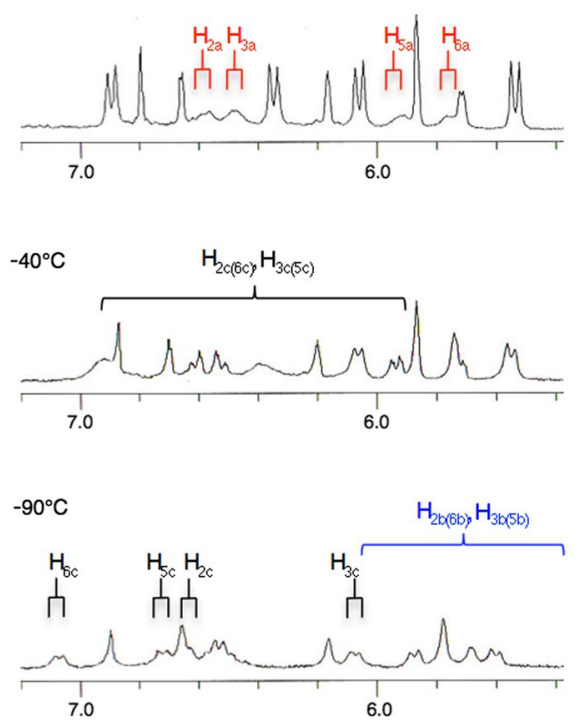

(b)

$100^{\circ} \mathrm{C}$

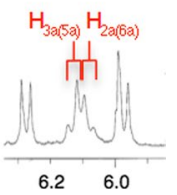

$80^{\circ} \mathrm{C}$

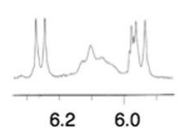

$60^{\circ} \mathrm{C}$
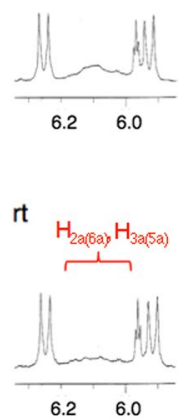

Fig. $18{ }^{1} \mathrm{H}-\mathrm{NMR}$ spectra $(300 \mathrm{MHz})$ of $\mathbf{7 9}$ at variable temperatures (a) in acetone- $d_{6}$; $\mathrm{rt}-90{ }^{\circ} \mathrm{C}$ and $(b)$ in DMSO- $d_{6} ; \mathrm{rt}-100{ }^{\circ} \mathrm{C}$

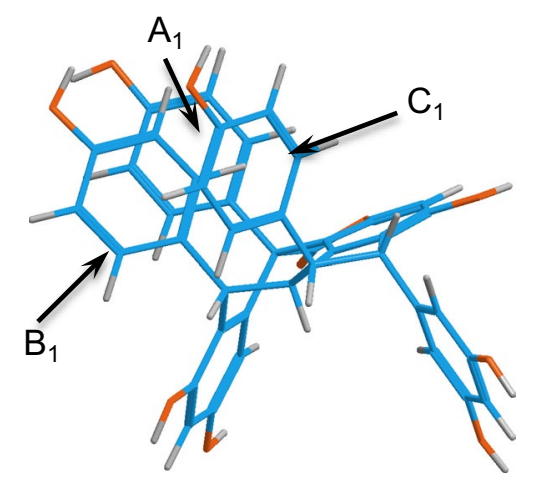

Fig. 19 Stereostructure of $\mathbf{7 9}$

difficulties in structural elucidation. Compound $\mathbf{5 5}$ exhibited broad signals in the entire region due to unstable conformation at ambient temperatures [25]. Indeed, in the spectrum, reducing the temperature results in a change in the signal features to clear; some substituents did not display signals. The significant features consist of signals for aromatic protons for ring $\mathrm{E}_{1}$ in various conditions (temperatures and solvents) as well as the completely overlapping methine signals.

$25^{\circ} \mathrm{C}$
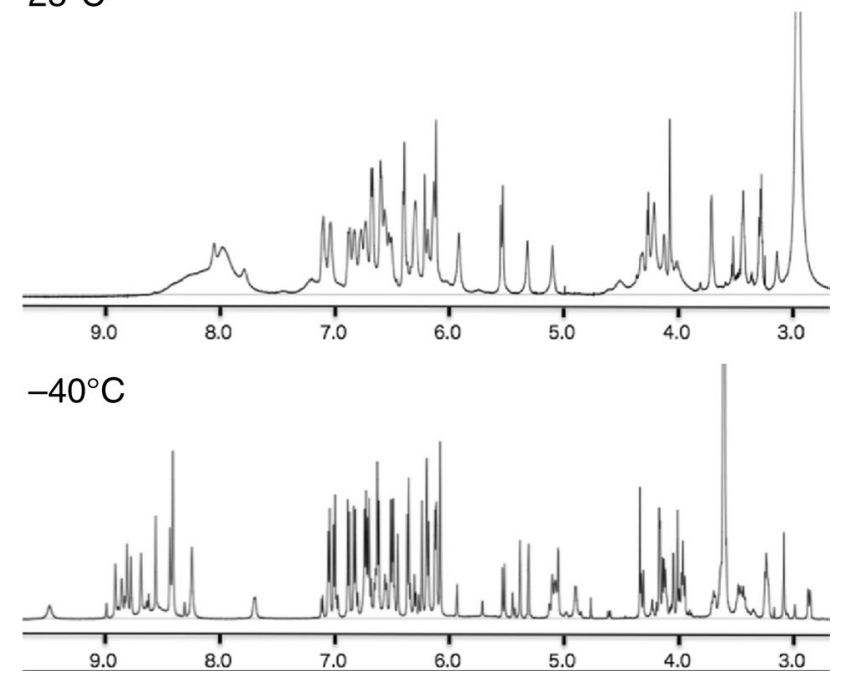

Fig. $20{ }^{1} \mathrm{H}$-NMR spectra $(600 \mathrm{MHz})$ of $\mathbf{1 1 4}$ in acetone- $d_{6}$ at $25{ }^{\circ} \mathrm{C}$ and $-40{ }^{\circ} \mathrm{C}$

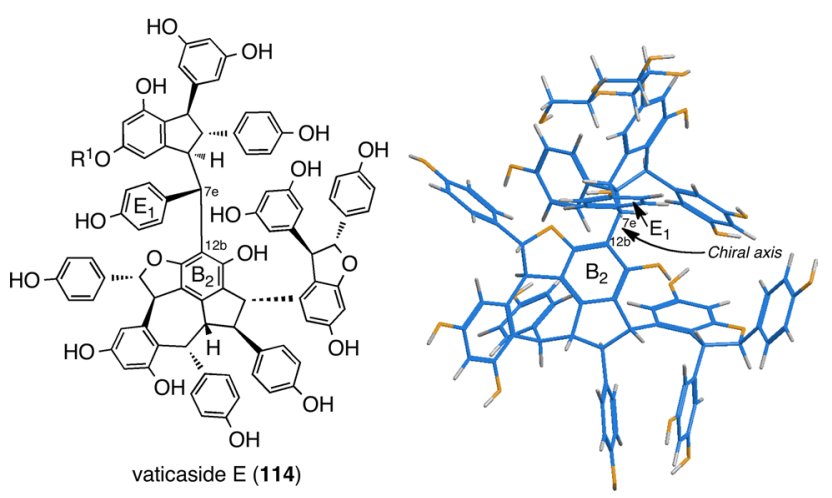

Fig. 21 Stereostructure of $\mathbf{1 1 4}$

Successful isolation of glucosides of $\mathbf{5 5}$ (vaticasides E (114) and F [25]) finally enable spectroscopic-data analysis, where clear NMR signals can be attributed to the weakened coasealence due to the enhanced hindered rotation of the $\mathrm{C}_{12}-\mathrm{C}_{7 \mathrm{e}}$ bond, which, in turn, results in the successful determination of 55 (Figs. 20, 21).

\section{Approaches to determine absolute configuration}

Some ROs with absolute configurations determined by different approaches have been summarized in the existing literature [78]: X-ray crystallographic analysis of their chemical derivatives using anomalous scattering of the bromine atom(s) ((-)-39 [7] and 99 [47]; the comparison of optical rotation and/or circular dichroism ((+)- and (-)5 [96], (+)-39 [97], 65 and 66 [52, 53], 63) and 64) [55], and modified Mosher's method (85) [84]; the comparison 
of the experimental and theoretical ECD spectra (42) [84]; the application of the olefin-cleavage strategy to a known compound to obtain ECDs of the newly separated products (68 and 69 [52, 53] as well as laetevirenol D [98]); the regioselective and stereospecific transformations of a hypothetical biogenetic precursor, (+)-5 ((+)-101 [99], (+)-vitisin A [100]); the acid-catalyzed skeletal conversion to obtain monoalkyl ether of the known derivative (38) [33]; assignment based on the comparison of the absolute configuration of the D- $\beta$-glucopyranosyl group (70-72)) [56, 59, 60]; comparison of experimental and theoretical electronic circular-dichroic spectra of the dehydroxylated derivative ((-)-31) [101]; comparative study using ECD with the help of the ECD of known compounds with previously determined absolute configurations ( 58 and $\mathbf{5 9}$ [78]). Currently, however, the absolute configurations of many ROs are yet to be determined. This is because, in typically cases, ROs are neither crystalline nor secondary alcohols, which is to say they are unsuitable for general methodologies. The application of a comparative study using an ECD database and X-ray analysis using porous complexes [102] is promising with respect to determining the absolute configuration of RO scaffold; however, this depends on a reliable chemical library. To be sure, the object of this review was not to provide a comprehensive example of the absolute configuration determination of ROs. Accordingly, a forthcoming review will be directed toward a better understanding of various methods to solve the issue in question.

\section{Concluding remarks}

Even though a considerable amount of knowledge is available with respect to the structural diversity of ROs in DPs (particularly, the $8-8^{\prime}$ and $8-10^{\prime}$ linked compounds), compounds with other link modes have not yet been comprehensively studied. This includes defining versatile structural motifs stemming from minor couplings and structural modifications (i.e., in terms of introduction of $O$-atom(s), dearomatization, rearrangement, tautomerization, and a hetero-coupling with other BBs), as well as deducing further stereochemical diversity in the chemical pool. Much work remains in clarifying the differences in physicochemical properties among the diverse stereoisomers that arise from enantiomerism, diastereomerism, and atropisomerism; these will be the subject of future work, as will be defining further RO structural diversity.

Acknowledgements The author gratefully acknowledge Dr. M. Iinuma, Prof. emeritus of Gifu Pharmaceutical University, for supervising study on the chemistry of RO as a core project of his laboratory (Laboratory of Pharmacognosy). I would like to thank all members of his group (past and present) who have participated in the schematic study for their efforts, their ideas, and their enthusiasm, rendering this line of research a true pleasure to pursue; their names are cited in the references.

I am grateful to Dr. Ryuichi Sawa and Dr. Yumiko Kubota, Laboratory of Structural Chemistry and Biology, Institute of Microbial Chemistry (IMC), Japan, for NMR and MS spectral measurements. I also sincerely thank Dr. Yoshikazu Takahashi, IMC, for his support for structural elucidation.

Open Access This article is licensed under a Creative Commons Attribution 4.0 International License (https://creativecommons.org/licenses/ by/4.0/), which permits use, sharing, adaptation, distribution and reproduction in any medium or format, as long as you give appropriate credit to the original author(s) and the source, provide a link to the Creative Commons licence, and indicate if changes were made. The images or other third party material in this article are included in the article's Creative Commons licence, unless indicated otherwise in a credit line to the material. If material is not included in the article's Creative Commons licence and your intended use is not permitted by statutory regulation or exceeds the permitted use, you will need to obtain permission directly from the copyright holder. To view a copy of this licence, visit http://creativecommons.org/licenses/by/4.0/

\section{References}

1. Sotheeswaran S, Pasupathy V (1993) Distribution of resveratrol oligomers in plants. Phytochemistry 32:1083-1092

2. Shen T, Wang X-N, Lou H-X (2009) Natural stilbenes: an overview. Nat Prod Rep 26:916-935

3. Xiao K, Zhang H-J, Xuan L-J, Zhang J, Xu Y-M, Bai D-L (2008) Stilbenoids: chemistry and bioactivities. In: Attaur R (ed) Studies in natural products chemistry. Elsevier, New York, pp 453-646

4. Rivière C, Pawlus AD, Mérillon J-M (2012) Natural stilbenoids: distribution in the plant kingdom and chemotaxonomic interest in Vitaceae. Nat Prod Rep 29:1317-1333

5. Simmathiri A, Jennifer M T (1998) A review of dipterocarps: taxonomy, ecology and silviculture. Center for International Forestry Research, pp 1-223

6. Ashton PS (1982) Dipterocarpaceae. In: Steenis CGGJ (ed) Flora Malesiana, Ser. I, Spermatophyta (flowering plants), vol 9, part 2. Martivus Nijhoff Publishers, Leiden, pp 237-552

7. Coggon P, King TJ, Wallwork SC (1966) The structure of hopeaphenol. Chem Commun 439-440

8. Keylor MH, Matsuura BS, Stephenson CRJ (2015) Chemistry and biology of resveratrol-derived natural products. Chem Rev 115:8976-9027. https://doi.org/10.1021/cr500689b

9. Jang M, Cai L, Udeani GO, Slowing KV, Thomas CF, Beecher CWW, Fong HHS, Farnsworth NR, Kinghorn AD, Mehta RG, Moon RC, Pezzuto JM (1997) Cancer chemopreventive activity of resveratrol, a natural product derived from grapes. Science 275:218. https://doi.org/10.1126/science.275.5297.218

10. Langcake P, Pryce RJ (1977) The production of resveratrol and the viniferins by grapevines in response to ultraviolet irradiation. Phytochemistry 16:1193-1196. https://doi.org/10.1016/S0031 -9422(00)94358-9

11. Langcake P, Pryce RJ (1977) A new class of phytoalexins from grapevines. Experientia 33:151-152. https://doi.org/10.1007/ BF02124034

12. Sotheeswaran S, Sultanbawa MUS, Surendrakumar S, Balasubramaniam S, Bladon P (1985) Polyphenols from dipterocarp species. Vaticaffinol and $\varepsilon$-viniferin. J Chem Soc Perkin Trans 1:159-162. https://doi.org/10.1039/P19850000159

13. Sultanbawa MUS, Surendrakumar S, Bladon P (1980) New antibacterial polyphenol, copalliferol A, from Vateria 
copallifera(retz.) alston (Dipterocarpaceae). J Chem Soc Chem Commun. https://doi.org/10.1039/C39800000619

14. Kurihara H, Kawabata J, Ichikawa S, Mishima M, Mizutani J (1991) Oligostilbenes from Carex kobomugi. Phytochemistry 30:649-653. https://doi.org/10.1016/0031-9422(91)83745-7

15. Lins AP, Felicio JD, Braggio MM, Roque LC (1991) A resveratrol dimer from Parthenocissus tricuspidata. Phytochemistry 30:3144-3146. https://doi.org/10.1016/S0031-9422(00)98274 $-8$

16. Ito $\mathrm{T}$, Tanaka $\mathrm{T}, \mathrm{Ki} \mathrm{N}$, Inuma $\mathrm{M}$, Takahashi $\mathrm{Y}$, Naganawa $\mathrm{H}$, Ohyama M, Nakanishi Y, Bastow KF, Lee KH (2001) A novel bridged stilbenoid trimer and four highly condensed stilbenoid oligomers in Vatica rassak. Tetrahedron 57:7309-7321. https:// doi.org/10.1016/S0040-4020(01)00697-4

17. Ito T, Tanaka T, Ido Y, Nakaya K, Inuma M, Takahashi Y, Naganawa H, Riswan S (2001) Five new oligostilbenes with one or two dihydrofurans from the stem bark of Vatica rassak. Heterocycles 55:557-567. https://doi.org/10.3987/COM-00-9139

18. Tanaka T, Ito T, Ki N, Inuma M, Takahashi Y, Naganawa H, Matsuura N, Ubukata M (2000) Vaticanol D, a novel resveratrol hexamer isolated from Vatica rassak. Tetrahedron Lett 41:79297932. https://doi.org/10.1016/S0040-4039(00)01383-6

19. Tanaka T, Ito T, Nakaya K, Iinuma M, Riswan S (2000) Oligostilbenoids in stem bark of Vatica rassak. Phytochemistry 54:63-69. https://doi.org/10.1016/s0031-9422(00)00026-1

20. Ito T, Tanaka T, Iinuma M, Nakaya K, Takahashi Y, Sawa R, Murata J, Darnaedi D (2004) Three new resveratrol oligomers from the stem bark of Vatica pauciflora. J Nat Prod 67:932-937. https://doi.org/10.1021/np030236r

21. Ito T, Tanaka T, Iinuma M, Iliya I, Ki N, Ali Z, Takahashi Y, Sawa R, Shirataki Y, Murata J (2003) New resveratrol oligomers in the stem bark of Vatica pauciflora. Tetrahedron 59:5347-5363. https://doi.org/10.1016/S0040-4020(03)00730-0

22. Abe N, Ito T, Oyama M, Sawa R, Takahashi Y, Iinuma M (2011) Resveratrol dimers with an oxabicyclo ring in Vatica albiramis. Heterocycles 83:571-580. https://doi.org/10.3987/ COM-10-12116

23. Abe N, Ito T, Oyama M, Sawa R, Takahashi Y, Iinuma M (2011) Resveratrol derivatives from Vatica albiramis. Chem Pharm Bull 59:452-457. https://doi.org/10.1248/cpb.59.452

24. Abe N, Ito T, Ohguchi K, Nasu M, Masuda Y, Oyama M, Nozawa Y, Ito M, Iinuma M (2010) Resveratrol Oligomers from Vatica albiramis. J Nat Prod 73:1499-1506. https://doi.org/10.1021/ np1002675

25. Ito T, Hara Y, Kubota Y, Sawa R, Iinuma M (2016) Absolute structure of resveratrol hexamers in Dipterocarpaceaeous plants. Tetrahedron 72:891-899. https://doi.org/10.1016/j. tet.2015.12.031

26. Ito T, Inuma M (2016) Occurrence of non-heterocyclic resveratrol tetramer in Vatica chinensis. Phytochem Lett 15:37-41. https ://doi.org/10.1016/j.phytol.2015.10.007

27. Ito T, Iinuma $M(2015)$ Isolation and structure elucidation of a novel resveratrol tetramer, vaticanol $\mathrm{K}$, with a fused 2,7-dihydrooxepine-quinone methide from Vatica chinensis. Tetrahedron Lett 56:5020-5023. https://doi.org/10.1016/j.tetlet.2015.07.022

28. Ito T, Masuda Y, Abe N, Oyama M, Sawa R, Takahashi Y, Chelladurai V, Iinuma M (2010) Chemical constituents in the leaves of Vateria indica. Chem Pharm Bull 58:1369-1378. https://doi. org/10.1248/cpb.58.1369

29. Ito T, Abe N, Masuda Y, Nasu M, Oyama M, Sawa R, Takahashi Y, Iinuma M (2009) Two novel resveratrol derivatives from the leaves of Vateria indica. Helv Chim Acta 92:195-208. https:// doi.org/10.1002/hlca.200800048

30. Ito T, Abe N, Oyama M, Iinuma M (2008) Oligostilbenoids from dipterocarpaceaeous plants: a new resveratrol tetramer from Vateria indica and the revised structure of isohopeaphenol. Helv
Chim Acta 91:1989-1998. https://doi.org/10.1002/hlca.20089 0214

31. Ito T, Tanaka T, Iinuma M, Ki N, Takahashi Y, Sawa R, Naganawa H, Chelladurai V (2003) Two new oligostilbenes with dihydrobenzofuran from the stem bark of Vateria indica. Tetrahedron 59:1255-1264. https://doi.org/10.1016/S0040-4020(03)00024-3

32. Ito T, Tanaka $\mathrm{T}$, Ki N, Iinuma M, Takahashi Y, Naganawa $\mathrm{H}$, Ohyama M, Nakanishi Y, Bastow KF, Lee KH (2001) A new resveratrol octamer, vateriaphenol A, in Vateria indica. Tetrahedron Lett 42:5909-5912. https://doi.org/10.1016/S0040 $-4039(01) 01137-6$

33. Ito T, Oyama M, Sajiki H, Sawa R, Takahashi Y, Iinuma M (2012) Absolute structure of shoreaketone: a rotational isomeric resveratrol tetramer in Dipterocarpaceaeous plants. Tetrahedron 68:2950-2960. https://doi.org/10.1016/j.tet.2012.02.036

34. Ito T, Ito H, Iinuma $M$ (2017) Absolute configuration of resveratrol oligomer glucosides isolated from the leaves of Upuna borneensis. Phytochem Lett 20:26-31. https://doi.org/10.1016/j. phytol.2017.03.006

35. Ito T, Abe N, Ali Z, Oyama M, Tanaka T, Sawa R, Takahashi Y, Murata J, Darnaedi D, Iinuma M (2009) Two new resveratrol tetramers from Upuna borneensis. Chem Pharm Bull 57:516519. https://doi.org/10.1248/cpb.57.516

36. Ito T, Abe N, Ali Z, Oyama M, Tanaka T, Murata J, Darnaedi D, Iinuma M (2007) Resveratrol tetramers with a C6-C3 or a C1 unit from Upuna borneensis. Chem Pharm Bull 55:1535-1539. https://doi.org/10.1248/cpb.55.1535

37. Ito T, Ali Z, Furusawa M, Iliya I, Tanaka T, Nakaya K, Murata J, Darnaedi D, Oyama M, Iinuma M (2005) New resveratrol tetramers from the stem bark of Upuna borneensis. Chem Biodivers 2:1673-1684. https://doi.org/10.1002/cbdv.200590137

38. Ito T, Furusawa M, Tanaka T, Ali Z, Iliya I, Nakaya K, Murata J, Darnaedi D, Iinuma M (2005) Resveratrol derivatives from Upuna borneensis. Chem Pharm Bull 53:219-224. https://doi. org/10.1248/cpb.46.663

39. Ito T, Iliya I, Tanaka T, Nakaya K, Akao Y, Nozawa Y, Murata J, Darnaedi D, Iinuma M (2005) Stilbenoids from leaves of Upuna borneensis. Heterocycles 65:173-179. https://doi.org/10.3987/ COM-04-10226

40. Ito T, Ali Z, Iliya I, Furusawa M, Tanaka T, Nakaya K, Takahashi Y, Sawa R, Murata J, Darnaedi D, Inuma M (2005) Occurrence of stilbene glucosides in Upuna borneensis. Helv Chim Acta 88:23-34. https://doi.org/10.1002/hlca.200490293

41. Ito T, Tanaka T, Ali Z, Akao Y, Nozawa Y, Takahashi Y, Sawa R, Nakaya K, Murata J, Darnaedi D, Iinuma M (2004) A new resveratrol hexamer from Upuna borneensis. Heterocycles 63:129-136. https://doi.org/10.3987/COM-03-9917

42. Ito T, Ali Z, Furusawa M, Iliya I, Tanaka T, Nakaya K, Murata J, Darnaedi D, Iinuma M (2006) Resveratrol oligomers and their $O$-glucosides from Cotylelobium lanceolatum. Chem Pharm Bull 54:363-367. https://doi.org/10.1248/cpb.54.363

43. Ito T, Ali Z, Tanaka T, Nakaya K, Murata J, Darnaedi D, Iinuma M (2006) Stilbenoids with one epoxy group from Cotylelobium lanceolatum. Heterocycles 68:1617-1630. https://doi. org/10.3987/com-06-10769

44. Ito T, Ali Z, Furusawa M, Iliya I, Tanaka T, Nakaya K, Murata J, Darnaedi D, Oyama M, Iinuma M (2005) Two novel trimeric resveratrol derivatives from Cotylelobium lanceolatum. Chem Biodivers 2:1200-1216. https://doi.org/10.1002/cbdv.200590091

45. Ito T, Abe N, Oyama M, Tanaka T, Murata J, Darnaedi D, Iinuma M (2009) Two novel resveratrol trimers from Dipterocarpus grandiflorus. Helv Chim Acta 92:1203-1216. https://doi. org/10.1002/hlca.200800429

46. Ito T, Tanaka $\mathrm{T}$, Iinuma $\mathrm{M}$, Nakaya $\mathrm{K}$, Takahashi $\mathrm{Y}$, Sawa R, Murata J, Darnaedi D (2004) Two new resveratrol (=5-[(1E)2-(4-hydroxyphenyl)ethenyl]-bezene-1,3-diol) tetramers with 
a tetrahydrofuran ring from Dipterocarpus grandiflorus. Helv Chim Acta 87:479-495. https://doi.org/10.1002/hlca.20049 0046

47. Ito T, Tanaka T, Iinuma M, Nakaya K, Takahashi Y, Nakamura H, Naganawa H, Riswan S (2003) A new dimeric stilbenoid with a five-membered lactone ring from Shorea hemsleyana. Helv Chim Acta 86:3394-3401. https://doi.org/10.1002/hlca.20039 0283

48. Tanaka T, Ito T, Nakaya K, Iinuma M, Takahashi Y, Naganawa $\mathrm{H}$, Riswan S (2001) Six new heterocyclic stilbene oligomers from stem bark of Shorea hemsleyana. Heterocycles 55:729-740. https ://doi.org/10.3987/COM-01-9166

49. Ito T, Tanaka T, Ido Y, Nakaya K, Iinuma M, Riswan S (2000) Four new stilbenoid $C$-glucosides isolated from the stem bark of Shorea hemsleyana. Chem Pharm Bull 48:1959-1963. https:// doi.org/10.1248/cpb.48.1959

50. Ito T, Tanaka T, Ido Y, Nakaya KI, Iinuma M, Riswan S (2000) Stilbenoids isolated from stem bark of Shorea hemsleyana. Chem Pharm Bull 48:1001-1005. https://doi.org/10.1248/cpb.48.1001

51. Ito T, Nishiguchi M, Iinuma M (2019) Three new resveratrol trimer Di-C-glucosides in Shorea uliginosa. Phytochem Lett 32:123-128. https://doi.org/10.1016/j.phytol.2019.05.012

52. Ito T, Hayashi K, Nishiguchi M, Hayashi T, Iinuma M (2018) Resveratrol oligomer $C$-glucosides and anti-viral resveratrol tetramers isolated from the stem bark of Shorea uliginosa. Phytochem Lett 28:1-7. https://doi.org/10.1016/j.phytol.2018.07.026

53. Ito T, Abe N, Oyama M, Iinuma M (2009) Absolute structures of $C$-glucosides of resveratrol oligomers from Shorea uliginosa. Tetrahedron Lett 50:2516-2520. https://doi.org/10.1016/j.tetle t.2009.03.043

54. Ito T, Furusawa M, Iliya I, Tanaka T, Ki N, Sawa R, Kubota Y, Takahashi Y, Riswan S, Iinuma M (2005) Rotational isomerism of a resveratrol tetramer, shoreaketone, in Shorea uliginosa. Tetrahedron Lett 46:3111-3114. https://doi.org/10.1016/j. tet.2012.02.036

55. Ito T, Nishiya K, Oyama M, Tanaka T, Murata J, Darnaedi D, Iinuma M (2013) Novel isolation of resveratrol dimer $O$-glucosides with enantiomeric aglycones from the leaves of Shorea cordifolia. Phytochem Lett 6:667-670. https://doi.org/10.1016/j. phytol.2013.08.001

56. Abe N, Ito T, Oyama M, Sawa R, Takahashi Y, Chelladurai V, Iinuma M (2011) Occurrence of $C$-glucoside of resveratrol Oligomers in Hopea parviflora. Chem Pharm Bull 59:239-248. https://doi.org/10.1248/cpb.59.239

57. Tanaka T, Iliya I, Ito T, Furusawa M, Nakaya KI, Iinuma M, Shirataki Y, Matsuura N, Ubukata M, Murata J, Simozono F, Hirai K (2001) Stilbenoids in lianas of Gnetum parvifolium. Chem Pharm Bull 49:858-862. https://doi.org/10.1248/cpb.49.858

58. Tanaka T, Ito T, Ido Y, Son TK, Nakaya K, Iinuma M, Ohyama M, Chelladurai V (2000) Stilbenoids in the stem bark of Hopea parviflora. Phytochemistry 53:1015-1019. https://doi. org/10.1016/S0031-9422(00)00019-4

59. Ito T, Hoshino R, Iinuma M (2015) Absolute configuration of resveratrol Oligomers isolated from Hopea utilis. Helv Chim Acta 98:32-46. https://doi.org/10.1002/hlca.201400146

60. Ito T, Hoshino R, Hara Y, Oyama M, Iinuma M (2013) Absolute configuration and conformational analysis of $C$-glucoside of a resveratrol trimer: structure of hopeaside E from Hopea utilis. Phytochem Lett 6:193-197. https://doi.org/10.1016/j.phyto 1.2013.01.003

61. Tanaka T, Ito T, Ido Y, Nakaya K, Iinuma M, Chelladurai V (2001) Hopeafuran and a $C$-glucosyl resveratrol isolated from stem wood of Hopea utilis. Chem Pharm Bull 49:785-787. https ://doi.org/10.1248/cpb.49.785

62. Vogt T (2010) Phenylpropanoid biosynthesis. Mol Plant 3:2-20. https://doi.org/10.1093/mp/ssp106
63. Sultanbawa MUS, Surendrakumar S, Wazeer MIM, Bladon P (1981) Novel resveratrol tetramer, vaticaffinol, from Vatica affinis Thw. (Dipterocarpaceae). J Chem Soc Chem Commun. https:// doi.org/10.1039/C39810001204

64. Oshima Y, Ueno Y (1993) Ampelopsins D, E, H and cisampelopsin E, oligostilbenes from Ampelopsis brevipedunculata var. Hancei roots. Phytochemistry 33:179-182. https://doi. org/10.1016/0031-9422(93)85418-Q

65. Oshima Y, Ueno Y, Hisamichi K, Takeshita M (1993) Ampelopsins $\mathrm{F}$ and $\mathrm{G}$, novel bridged plant oligostilbenes from Ampelopsis brevipedunculata var. hancei roots (Vitaceae). Tetrahedron 49:5801-5804. https://doi.org/10.1016/S0040 $-4020(01) 87946-1$

66. Diyasena MNC, Sotheeswaran S, Surendrakumar S, Balasubramanian S, Bokel M, Kraus W (1985) Balanocarpol, a new polyphenol from Balanocarpus zeylanicus (Trimen) and Hopea jucunda (Thw.) (Dipterocarpaceae). J Chem Soc Perkin Trans 1:1807-1809. https://doi.org/10.1039/P19850001807

67. Dai JR, Hallock YF, Cardellina JH 2nd, Boyd MR (1998) HIVinhibitory and cytotoxic oligostilbenes from the leaves of Hopea malibato. J Nat Prod 61:351-353. https://doi.org/10.1021/np970 $519 \mathrm{~h}$

68. Saraswathy A, Purushothaman KK, Patra A, Dey AK, Kundu AB (1992) Shoreaphenol, a polyphenol from Shorea robusta. Phytochemistry 31:2561-2562. https://doi.org/10.1016/00319422(92)83330-2

69. Weber JFF, Wahab IA, Marzuki A, Thomas NF, Kadir AA, Hadi AHA, Awang K, Latiff AA, Richomme P, Delaunay J (2001) Heimiol A, a new dimeric stilbenoid from Neobalanocarpus heimii. Tetrahedron Lett 42:4895-4897. https://doi.org/10.1016/S0040 $-4039(01) 00772-9$

70. Tanaka T, Ito T, Inuma M, Ohyama M, Ichise M, Tateishi Y (2000) Stilbene oligomers in roots of Sophora davidii. Phytochemistry 53:1009-1014. https://doi.org/10.1016/s0031 -9422(00)00016-9

71. Ohyama M, Tanaka T, Iinuma M, Burandt CL (1998) Phenolic compounds isolated from the roots of Sophora stenophylla. Chem Pharm Bull 46:663-668. https://doi.org/10.1248/cpb.46.663

72. Suzuki K, Shimizu T, Kawabata J, Mizutani J (1987) New 3 , 5, 4'-trihydroxystilbene (Resveratrol) Oligomers from Carex Fedia Nees Var. miyabei (Franchet) T. Koyama (Cyperaceae). Agric Biol Chem 51:1003-1008. https://doi.org/10.1271/bbb19 61.51.1003

73. Pryce RJ, Langcake $P(1977) \alpha$-Viniferin: an antifungal resveratrol trimer from grapevines. Phytochemistry $16: 1452-1454$. https ://doi.org/10.1016/S0031-9422(00)88809-3

74. PCMODEL 9.3 SS, Box 3076, Bloomington, IN 47402-3076

75. Seo E-K, Chai H, Constant HL, Santisuk T, Reutrakul V, Beecher CWW, Farnsworth NR, Cordell GA, Pezzuto JM, Kinghorn AD (1999) Resveratrol tetramers from Vatica diospyroides. J Org Chem 64:6976-6983. https://doi.org/10.1021/jo9902087

76. Bao L, Ma X, Song X, Wang M, Liu H (2010) Two new resveratrol tetramers isolated from Cayratia japonica (Thunb.) Gagn. with strong inhibitory activity on fatty acid synthase and antioxidant activity. Chem Biodivers 7:2931-2940. https://doi. org/10.1002/cbdv.200900394

77. Adesanya SA, Nia R, Martin M-T, Boukamcha N, Montagnac A, Païs M (1999) Stilbene derivatives from Cissus quadrangularis. J Nat Prod 62:1694-1695. https://doi.org/10.1021/np9902744

78. Ito T, Ito H, Nehira T, Sawa R, Iinuma M (2014) Structure elucidation of highly condensed stilbenoids: chiroptical properties and absolute configuration. Tetrahedron 70:5640-5649. https:// doi.org/10.1016/j.tet.2014.06.074

79. Aminah NS, Achmad SA, Aimi N, Ghisalberti EL, Hakim EH, Kitajima M, Syah YM, Takayama H (2002) Diptoindonesin A, a new C-glucoside of $\varepsilon$-viniferin from Shorea 
seminis (Dipterocarpaceae). Fitoterapia 73:501-507. https://doi. org/10.1016/s0367-326x(02)00179-x

80. Lins AP, Ribeiro MNDS, Gottlieb OR, Gottlieb HE (1982) Gnetins: resveratrol Oligomers from Gnetum species. J Nat Prod 45:754-761. https://doi.org/10.1021/np50024a022

81. Ohyama M, Tanaka T, Iinuma M (1994) A novel stilbene tetramer, leachianol C, isolated from Sophora leachiana. Tetrahedron Lett 35:7817-7820. https://doi.org/10.1016/00404039(94)80126-6

82. Ohyama M, Tanaka T, Iinuma M, Goto K (1994) Two novel resveratrol trimers, Leachianols A and B, from Sophora leachiana. Chem Pharm Bull 42:2117-2120. https://doi.org/10.1248/ cpb.42.2117

83. Kawabata J, Mishima M, Kurihara H, Mizutani J (1991) Kobophenol B, a tetrastilbene from Carex pumila. Phytochemistry 30:645-647. https://doi.org/10.1016/0031-9422(91)83744-6

84. Qin YH, Zhang J, Cui JT, Guo ZK, Jiang N, Tan RX, Ge HM (2011) Oligostilbenes from Vatica mangachapoi with xanthine oxidase and acetylcholinesterase inhibitory activities. RSC Adv 1:135-141. https://doi.org/10.1039/C1RA00007A

85. Ge HM, Yang WH, Shen Y, Jiang N, Guo ZK, Luo Q, Xu Q, Ma J, Tan RX (2010) Immunosuppressive resveratrol aneuploids from Hopea chinensis. Chemistry 16:6338-6345. https://doi. org/10.1002/chem.201000230

86. Luo HF, Zhang LP, Hu CQ (2001) Five novel oligostilbenes from the roots of Caragana sinica. Tetrahedron 57:4849-4854. https ://doi.org/10.1016/S0040-4020(01)00427-6

87. Sahidin HEH, Juliawaty LD, Syah YM, bin Din L, Ghisalberti EL, Latip J, Said IM, Achmad SA (2005) Cytotoxic properties of oligostilbenoids from the tree barks of Hopea dryobalanoides. J Biosci 60:723-727. https://doi.org/10.1515/znc-2005-9-1011

88. Ge HM, Zhu CH, Shi DH, Zhang LD, Xie DQ, Yang J, Ng SW, Tan RX (2008) Hopeahainol A: an acetylcholinesterase inhibitor from Hopea hainanensis. Chem A Euro J 14:376-381. https:// doi.org/10.1002/chem.200700960

89. Liu JY, Ye YH, Wang L, Shi DH, Tan RX (2005) New resveratrol oligomers from the stem bark of Hopea hainanensis. Helv Chim Acta 88:2910-2917. https://doi.org/10.1002/hlca.200590234

90. Tanaka T, Ito T, Nakaya K, Iinuma M, Takahashi Y, Naganawa H, Ohyama M, Nakanishi Y, Bastow KF, Lee K-H, Matsuura N, Ubukata M, Shirataki Y (2000) Chemical constituents of Dipterocarpaceaeous plants and their bioactivities. In: 42nd symposium on the chemistry of natural products, vol 42. pp 493-498. https://doi.org/10.24496/tennenyuki.42.0_493

91. Hirano Y, Kondo R, Sakai K (2003) Novel stilbenoids isolated from the heartwood of Shorea laeviforia. J Wood Sci 49:53-58. https://doi.org/10.1007/s100860300009

92. Muhammad N, Din LB, Sahidin I, Hashim SF, Ibrahim N, Zakaria Z, Yaacob WA (2012) Acuminatol and other antioxidative resveratrol oligomers from the stem bark of Shorea acuminata. Molecules 17:9043-9055. https://doi.org/10.3390/molecules1 7089043

93. Tanaka T, Ohyama M, Morimoto K, Asai F, Iinuma M (1998) A resveratrol dimer from Parthenocissus tricuspidata. Phytochemistry 48:1241-1243. https://doi.org/10.1016/S0031 -9422(97)00898-4

94. Umezawa Y, Tsuboyama S, Takahashi H, Uzawa J, Nishio M (1999) $\mathrm{CH} \pi$ interaction in the conformation of organic compounds. A database study. Tetrahedron 55:10047-10056. https ://doi.org/10.1016/S0040-4020(99)00539-6

95. Nishio M, Umezawa Y, Hirota M, Takeuchi Y (1995) The CH/ $\pi$ interaction: significance in molecular recognition. Tetrahedron 51:8665-8701. https://doi.org/10.1016/0040-4020(94)01066-9

96. Kurihara H, Kawabata J, Ichikawa S, Mizutani J (1990) $(-)-\varepsilon$-Viniferin and related oligostilbenes from Carex pumila Thunb. (Cyperaceae). Agric Biol Chem 54:1097-1099. https:// doi.org/10.1271/bbb1961.54.1097

97. Ito J, Niwa M, Oshima Y (1997) A new hydroxystilbene tetramer named isohopeaphenol from Vitis vinifera 'Kyohou'. Heterocycles 45:1809-1813. https://doi.org/10.3987/COM-97-7870

98. He S, Wu B, Pan Y, Jiang L (2008) Stilbene oligomers from Parthenocissus laetevirens: isolation, biomimetic synthesis, absolute configuration, and implication of antioxidative defense system in the plant. J Org Chem 73:5233-5241. https://doi.org/10.1021/ jo8001112

99. Takaya Y, Yan KX, Terashima K, Ito J, Niwa M (2002) Chemical determination of the absolute structures of resveratrol dimers, ampelopsins A, B, D and F. Tetrahedron 58:7259-7265. https:// doi.org/10.1016/S0040-4020(02)00785-8

100. Takaya Y, Yan KX, Terashima K, He YH, Niwa M (2002) Biogenetic reactions on stilbenetetramers from Vitaceaeous plants. Tetrahedron 58:9265-9271. https://doi.org/10.1016/S0040 $-4020(02) 01191-2$

101. Ito T, Nehira T (2014) Dehydroxylation of stilbenoid oligomers: absolute configuration determination via comparison of experimental and theoretical electronic circular dichroic spectra. Tetrahedron Lett 55:314-318. https://doi.org/10.1016/j.tetle t.2013.10.106

102. Inokuma Y, Yoshioka S, Ariyoshi J, Arai T, Hitora Y, Takada K, Matsunaga S, Rissanen K, Fujita M (2013) X-ray analysis on the nanogram to microgram scale using porous complexes. Nature 495:461-466. https://doi.org/10.1038/nature11990

Publisher's Note Springer Nature remains neutral with regard to jurisdictional claims in published maps and institutional affiliations. 